\title{
Les fortifications médiévales et modernes de la ville de Nantes : un état des connaissances historiques, archéologiques et topographiques
}

Nantes' Medieval and Modern Town Fortifications: A Historical, Archaeological and Topographical State of Knowledge

Mittelalterliche und moderne Befestigungsanlagen der Stadt Nantes: ein

Zustand des historischen, archäologischen und topographischen Wissens

\section{Camille Dreillard}

\section{OpenEdition}

\section{Journals}

Édition électronique

URL : https://journals.openedition.org/rao/4250

DOI : 10.4000/rao.4250

ISSN : 1775-3732

Éditeur

Presses universitaires de Rennes

Édition imprimée

Date de publication : 31 décembre 2017

Pagination : 323-352

ISBN : 978-2-7535-7540-0

ISSN : 0767-709X

\section{Référence électronique}

Camille Dreillard, «Les fortifications médiévales et modernes de la ville de Nantes : un état des connaissances historiques, archéologiques et topographiques », Revue archéologique de l'Ouest [En ligne], 34 | 2017, mis en ligne le 13 juin 2020, consulté le 22 août 2022. URL : http:// journals.openedition.org/rao/4250; DOI : https://doi.org/10.4000/rao.4250 


\title{
Les fortifications médiévales et modernes de la ville de Nantes : un état des connaissances historiques, archéologiques et topographiques
}

\author{
Nantes' Medieval and Modern Town Fortifications: A Historical, \\ Archaeological and Topographical State of Knowledge
}

\author{
Camille Dreillard ${ }^{a}$
}

\begin{abstract}
Résumé : En s’appuyant principalement sur les sources textuelles de première main, les données de fouilles archéologiques et les documents planimétriques, l'étude a pour objectif de proposer un état des connaissances des fortifications médiévales et modernes de la ville de Nantes. Cette synthèse vise à retracer l'évolution chronologique, topographique et typologique des fortifications de la ville, depuis les premiers remaniements de l'enceinte antique, jusqu'aux travaux de démantèlement du XvıII ${ }^{\mathrm{e}}$ siècle. Plusieurs grandes phases de constitution du dispositif défensif urbain sont ainsi abordées, comme la mise en place des réduits fortifiés intra-muros et extra-muros dans le courant des $\mathrm{X}^{\mathrm{e}}$-XII $\mathrm{XI}^{\mathrm{e}}$ siècles, l'édification de la grande enceinte urbaine ducale au début du XIII ${ }^{\mathrm{e}}$ siècle, les travaux de mise en défense de la ville pendant la guerre de Succession de Bretagne et la guerre de Cent Ans, l'adaptation des fortifications à l'artillerie à poudre au Xve siècle, ou encore les aménagements liés aux guerres de Religion. Quelques aspects plus thématiques sont aussi développés, comme la question des mottes périurbaines ou les caractéristiques techniques du chantier de reconstruction de l'enceinte urbaine au $\mathrm{Xv}^{\mathrm{e}}$ siècle. Une attention particulière est également portée à la présentation des dernières données archéologiques ainsi qu'aux lacunes documentaires, parfois à l'origine d'une « tradition » historiographique locale approximative.
\end{abstract}

\begin{abstract}
Based mainly on primary written sources, archaeological data and cartographic documents, this study's objective is to overview Nantes' medieval and modern town fortifications (Loire-Atlantique, France). Even though little is known of the fortification's whereabouts, the main goal of this study is to retrace the chronological, topographical and typological development of the town wall from the Roman period to its dismantlement in the $18^{\text {th }}$ century. The city walls were built during several major phases: the enclosure walls were built during the $10^{\text {th }}-12^{\text {th }}$ centuries, the great city's wall was built in the early $13^{\text {th }}$ century, the defensive works were constructed during Brittany's succession war and Hundred Years War and the fortification was adapted to powder artillery during the $15^{\text {th }}-16^{\text {th }}$ century. Other issues such as the question of the suburban hills or the way the walls were rebuilt during the $15^{\text {th }}$ century are also discussed here.
\end{abstract}

Mots clés : Nantes, fortifications urbaines, enceinte urbaine, château, castrum, travaux de fortification, Moyen Âge, période moderne, topographie urbaine, histoire urbaine.

Keywords : Nantes, urban fortifications, town walls, castle, castrum, fortifications works, Middle Ages, modern period, urban topography, urban history.

L'étude historique et archéologique des fortifications médiévales et modernes de la ville de Nantes présentée dans cet article de synthèse s'appuie principalement sur les données rassemblées dans le cadre d'un Master Recherche
"Archéologie et Histoire " réalisé à l'université de Nantes ${ }^{1}$ Ces recherches ont été initiées et motivées par l'absence d'étude de synthèse exclusivement consacrée aux fortifications urbaines nantaises.

\footnotetext{
"Archéologue contractuel, diplômé de l'université de Nantes, Master "Archéologie et Histoire ", spécialité Archéologie des Sociétés et des Territoires en France métropolitaine. (camille.dreillard@gmail.com)

1. Ces recherches, effectuées sous la direction d'Y. Henigfeld (université de Nantes) et avec l'assistance scientifique et logistique des archéologues de la Direction du Patrimoine et de l'Archéologie de Nantes Métropole, ont donné lieu à la rédaction de deux mémoires universitaires (Dreillard, 2014; 2015).
} 
Les premières considérations et observations à caractère " historique " sur les fortifications de la ville sont mentionnées dans les récits des chroniqueurs ${ }^{2}$ et des voyageurs ${ }^{3}$ des $\mathrm{XVI}^{\mathrm{e}}$ et XVII ${ }^{\mathrm{e}}$ siècles. Dans le courant des XVIII ${ }^{\mathrm{e}}$ et XIX ${ }^{\mathrm{e}}$ siècles, des érudits ecclésiastiques, puis des archivistes, entreprennent de constituer de grands recueils de sources textuelles pour retracer et écrire l'histoire de Nantes et de la Bretagne en général ${ }^{4}$. Ces ouvrages apportent donc de précieux éléments de compréhension de l'évolution des fortifications de la ville. Très souvent utilisés en tant que sources de première main, ils ont profondément marqué l'historiographie locale mais n'ont cependant que rarement bénéficié d'analyses critiques. D'un point de vue plus " archéologique ", plusieurs campagnes de fouilles ont été réalisées à l'occasion de travaux d'urbanisme au cours du XIXe siècle et pendant la première moitié du $\mathrm{Xx}^{\mathrm{e}}$ siècle. Sans revenir en détail sur le développement de l'archéologie à Nantes (Pirault et Rouaud-Rouazé, 1996; Monteil, 2011), il convient toutefois de préciser qu'au-delà de quelques comptes-rendus et observations effectués sur des vestiges médiévaux ${ }^{5}$, la majorité des recherches de la période s'intéresse avant tout aux origines antiques de la ville. La connaissance des fortifications médiévales de Nantes progresse après la Seconde Guerre mondiale, dans le cadre de l'essor des études universitaires basées sur l'examen des sources textuelles manuscrites. Les fortifications y sont abordées au sein de thématiques de recherches plus larges ${ }^{6}$, et les grandes phases de construction sont rappelées succinctement au sein d'études diachroniques sur l'histoire de la ville7. Ce n'est qu'à partir des années 1990 que la ville de Nantes « redécouvre " peu à peu ses anciens murs d'enceinte, par l'intermédiaire d'opérations archéologiques préventives ${ }^{8}$, complétées par quelques études universitaires ${ }^{9}$, qui viennent

2. Voir notamment les chroniques d'Alain Bouchart, de Bertrand d'Argentré, de Pierre Le Baud et de Jean de Saint-Paul.

3. Les carnets de voyages de François-Nicolas Baudot dit DubuissonAubenay (Croix, 2006) ou encore le journal du peintre hollandais Willem Shellinks (Robrie, 1970).

4. Parmi d'autres, voir par exemple les ouvrages de Dom Lobineau (1707; 1741-1756), de Dom Morice (1742-1746), de N. Travers (1836), d'A. de La Borderie $(1885 ; 1888 ; 1896-1914 ; 1902 ; 1991)$, S. de La Nicollière-Teijeiro (1883) et R. Blanchard (1889-1895).

5. En particulier les observations de J.-T.-A. Vandier (1847) sur le Bouffay, de G. Durville $(1900 ; 1913)$ au niveau de l'évêché, et de J. StanyGauthier (1937) au château des ducs.

6. Par exemple : la construction à Nantes au Xve siècle (Le Mené, 1961) ou le réseau urbain breton médiéval (Leguay, 1981).

7. Comme les « Histoires » de Nantes de P. Bois (1977), de P. Lelièvre (1988) ou encore de O. Pétré-Grenouilleau (2003).

8. Au niveau de la porte Sauvetout par F. Guérin (1995; 1998), J. Martineau (2001) et N. Lacoste (2012); de la porte Saint-Pierre par N. Lacoste (2014); de la porte de la Poissonnerie et des courtines attenantes par M. Laurens-Berge (2014a; 2014b) et S. Augry (2014); du château des ducs sous la direction de F. Mercier (1993) et J. Pascal (2006; 2007a; 2007b; 2008).

9. Réalisées par A. Armide $(2005,2011)$ et M. Pacaud $(2010 ; 2014)$. renouveler la compréhension et l'approche de l'évolution des fortifications dans l'espace urbain (fig. 1).

L'ambition principale de cette étude est donc de réaliser un état des connaissances actuelles de l'évolution des fortifications dans l'espace urbain sur le temps long, de façon à faciliter d'éventuelles recherches historiques ou opérations archéologiques à venir. Afin de s'affranchir des pièges de la tradition historiographique, et de faire le point sur la chronologie historique, cette synthèse s'appuie principalement sur les sources textuelles de première main publiées (chroniques et recueils d'actes) ou manuscrites (registres de comptes de construction), sur les derniers rapports d'opérations archéologiques, ainsi que sur les documents iconographiques et planimétriques anciens.

\section{LES FORTIFICATIONS DU BAS-EMPIRE AUX RAIDS VIKINGS : LE MUR DE CITÉ COMME PRINCIPALE DÉFENSE $\left({ }^{\mathrm{E}}{ }^{\mathrm{E}}\right.$ SIÈCLE-DÉBUT $\mathrm{X}^{\mathrm{E}}$ SIÈCLE)}

\section{L'enceinte antique}

Nantes (Condevicnum ou Portus Namnetum), capitale des Namnètes située à la confluence de la Loire et de l'Erdre, se dote d'une enceinte vers la fin du III $^{\mathrm{e}}$ siècle ou au début du $\mathrm{IV}^{\mathrm{e}}$ siècle. Le territoire intra-muros de la ville du Bas-Empire occupe une surface d'environ 18 ha (Monteil, 2008, p. 16). Si le tracé général du mur du castrum peut-être restitué grâce aux sections encore conservées en élévation et aux observations archéologiques réalisées depuis le $\mathrm{XIX}^{\mathrm{e}}$ siècle, il reste encore parfois méconnu, notamment au niveau du front sud (fig. 2). Le mur d'enceinte, qui devait avoisiner en moyenne quatre mètres d'épaisseur, est flanqué de tourelles demi-circulaires pleines et dispose d'au moins six portes (Pirault et Rouaud-Rouaze, 1997, p. 13). Son élévation est composée d'une alternance d'assises de petits blocs de granit quadrangulaires et d'assises de briques (fig. 3), tandis que ses fondations sont constituées de matériaux de réemplois, comme des stèles funéraires ou des bornes milliaires, ainsi que de blocs irréguliers de nature diverse (Lacoste, 2014, p. 55-56). La compréhension du devenir de ce premier mur d'enceinte à la fin de l'Antiquité tardive et pendant la plus grande partie du premier Moyen Âge se heurte à l'indigence des données textuelles et archéologiques. En effet, pour cette période, la connaissance du paysage monumental de la ville, qui devient siège d'évêché dans le courant du v siècle, se résume avant tout aux édifices religieux urbains et suburbains, dont un état des connaissances a été réalisé par M. Monteil (2008).

Le mur d'enceinte du Bas-Empire semble donc se maintenir comme la principale défense de la ville jusqu'au début du $\mathrm{x}^{\mathrm{e}}$ siècle. Les premières modifications du dispositif défensif 


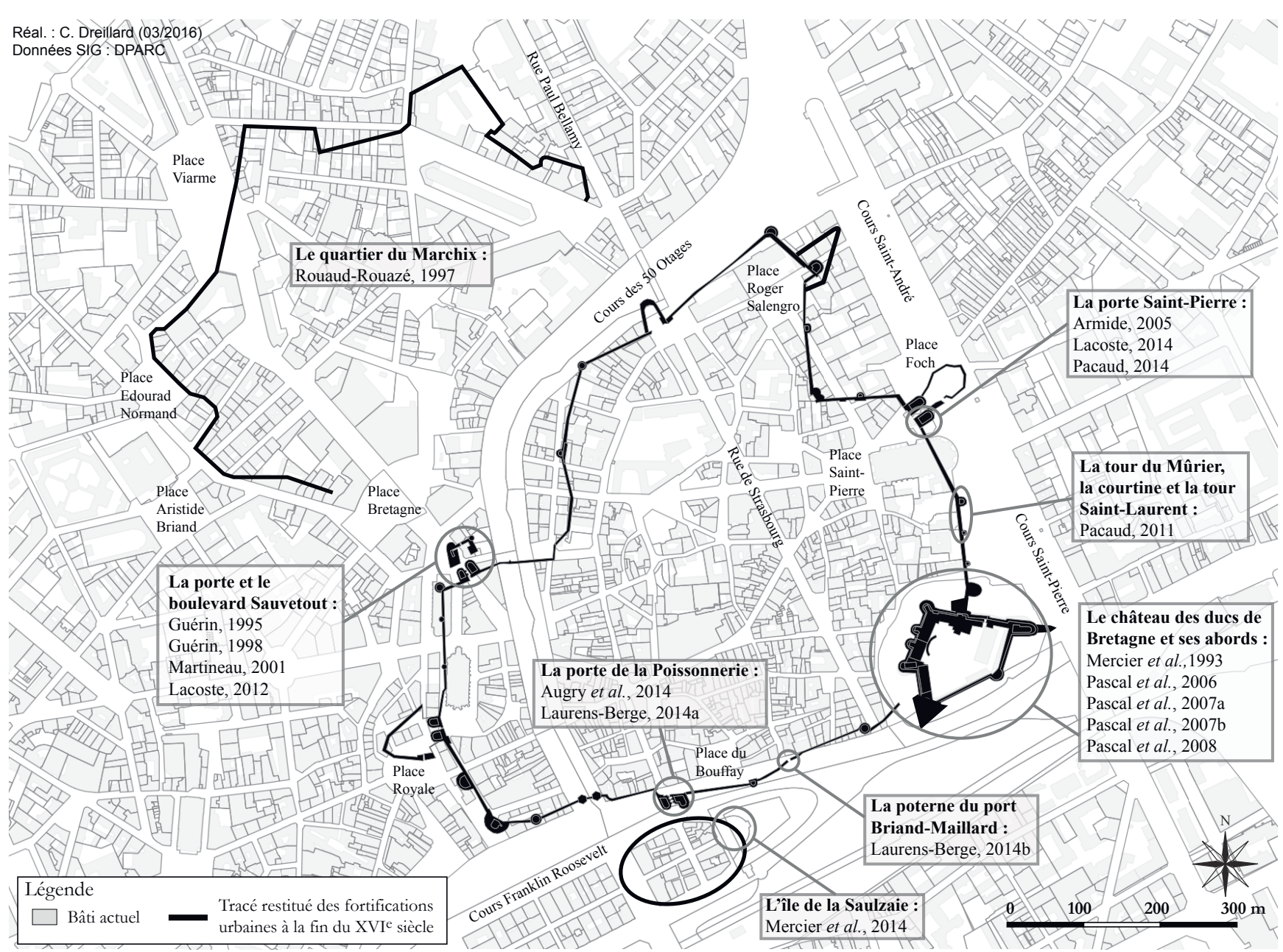

Figure 1 : Les principales études et opérations archéologiques récentes sur les fortifications médiévales et modernes (réal.: C. Dreillard; données SIG : DPARC).

Figure 1: Latest studies of medieval and modern urban fortifications.

urbain hérité de l'Antiquité attestées par les sources textuelles datent en effet de cette période. Elles sont mentionnées dans la Chronique de Nantes, ouvrage en latin vraisemblablement rédigé au XI ${ }^{\mathrm{e}}$ siècle, dont les divers fragments ont été rassemblés et publiés par l'archiviste R. Merlet (1896), accompagnés d'une traduction française établie par le chroniqueur Pierre Le Baud au Xve siècle. Les fortifications y sont notamment décrites à l'occasion des raids des Vikings sur la ville et la région ligérienne. Ces derniers attaquent en effet Nantes en 843, en 853, et en 919 (Guigon, 1997, p. 23). Selon la Chronique, lors de leur première attaque, les Scandinaves escaladent les murs de la cité à l'aide d'échelles, ce qui laisse entendre que l'enceinte antique dispose alors toujours d'une élévation assez importante pour jouer un rôle défensif. La Chronique insiste d'ailleurs plus sur le défaut de surveillance des habitants, que sur une défaillance du dispositif défensif : "[Les normands] vindrent aborder leur navire jouxte les murs de la cité de Nantes, laquelle ilz avironnèrent d'un costé et d'autre [...] et, les ungs rampans contre monts les murs par eschielles, les autres desfroissans et pénétrans les clostures, nul ne leur déneyant l'entrée, entrèrent en dépourveu en laditte cité le sollempnel jour de la Nativité sainct Jehan-Baptiste. " (Merlet, 1896, p. 15). Plusieurs tours semblent par exemple encore flanquer le mur de ville, puisque vers 850 , c'est le comte de Nantes Lambert qui cherche à faire "édifier sa maison en la souveraine tour de la cité" ("voluit domum suam in principali arce hujus urbis aedeficare») (Merlet, 1896, p. 27).

\section{La fortification de l'évêque Foucher}

Ce n'est que vers les années 900-910 que la Chronique fournit des indications sur la faible valeur défensive et le mauvais état de conservation de l'enceinte antique. En effet, celle-ci semble alors "desrompue par parties » et trop grande 


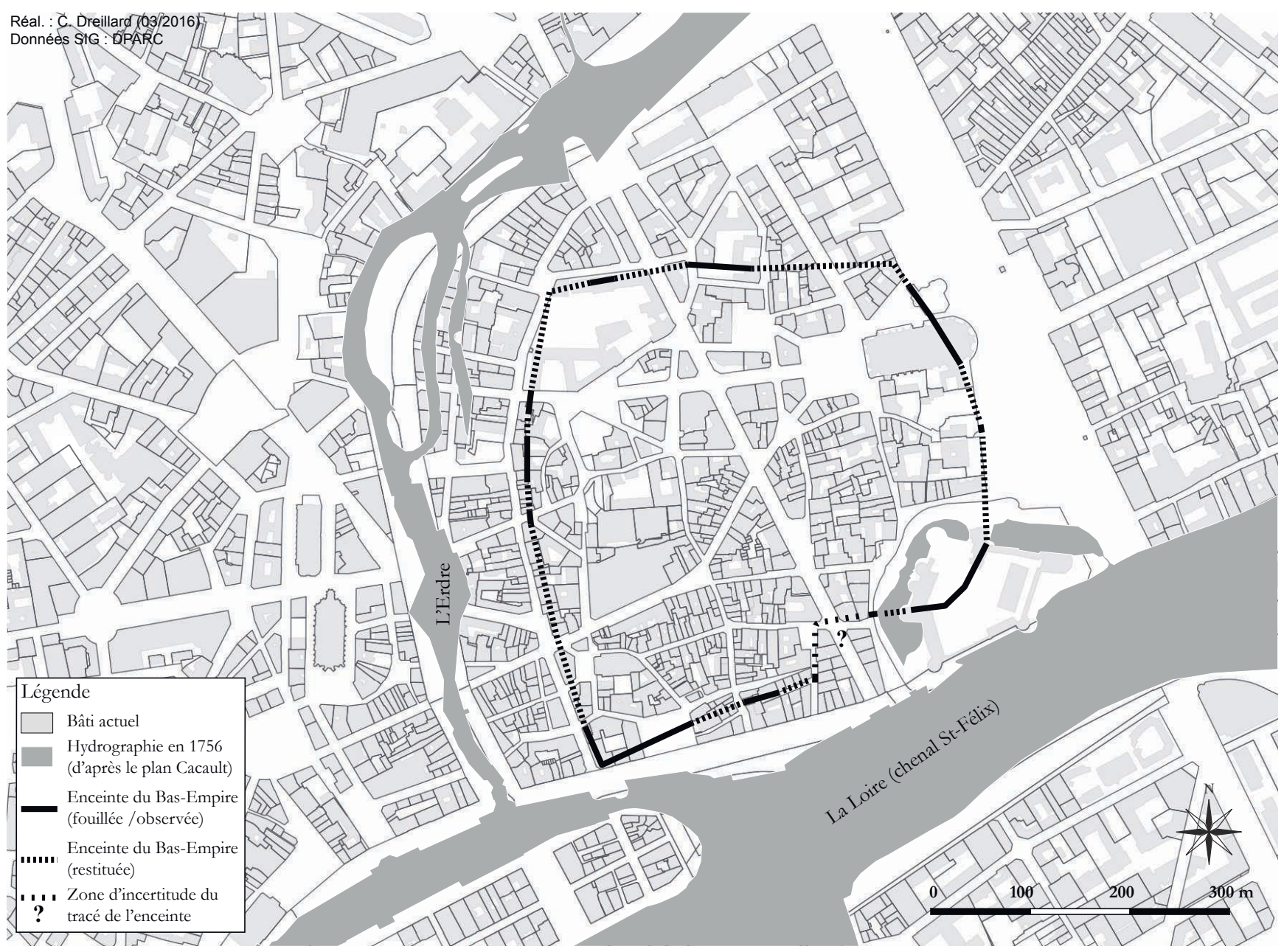

Figure 2 : Proposition de restitution des fortifications du Bas-Empire (réal. : C. Dreillard; données SIG : DPARC).

Figure 2: Urban fortifications at the end of the Roman period.

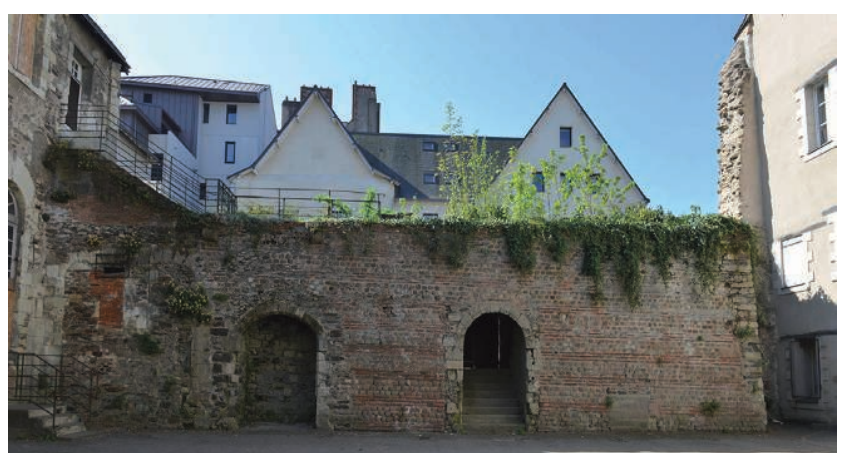

Figure 3 : Section de l'enceinte antique (parement extra-muros) conservée dans la cour de l'actuelle école Saint-Pierre et ancien couvent des Cordeliers (cliché P. Jean, Archives municipales de Nantes).

Figure 3: Section of the roman wall in Saint-Pierre schoolyard. pour être convenablement défendue, ce qui pousse l'évêque Foucher/Fulcherius à faire construire une fortification maçonnée ("castrum muro factum ») plus réduite autour de la cathédrale Saint-Pierre-et-Saint-Paul, qu'il fait également agrandir (Merlet, 1896, p. 77-79). Une petite section ${ }^{10}$ de ce mur d'enceinte a peut-être été mise au jour à l'occasion des fouilles de l'évêché de Nantes réalisées au début du Xx ${ }^{e}$ siècle. Si pour G. Durville (1913, p. 75) ce mur de blocs de schiste grossièrement équarris, non assisé mais parementé, et situé à $5 \mathrm{~m}$ en avant du mur du castrum, corresponds avec certitude à l'enceinte de l'évêque Foucher, l'étude archéologique réalisée en 2012 par le service archéologique municipal reste plus mesurée, précisant que la chronologie relative n'atteste que d'une construction du mur (MR 1027) entre le viII et le $\mathrm{Xv}^{e}$ siècle (Lacoste, 2014, p. 45) (fig. 4 et 5). La forme et

10. Environ 1,50 m d'élévation, conservée sur $5 \mathrm{~m}$ de long, et réemployée dans l'épaisseur du mur de gorge de la tour de l'Évêché ( $\mathrm{Xv}^{\mathrm{e}}$ siècle). 


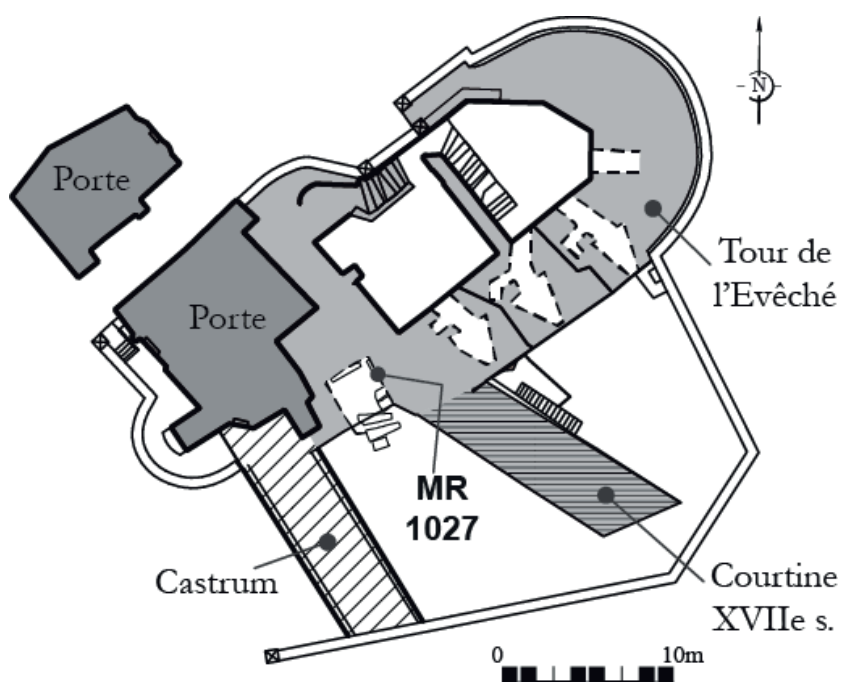

Figure 4 : Plan des vestiges des fortifications conservés aux abords de la porte Saint-Pierre (réal. N. Lacoste, DPARC).

Figure 4: Map of the fortifications remains near the Saint-Pierre gate.

l'emprise de cette fortification épiscopale demeurent donc très hypothétiques. Avec la prudence qui s'impose tant les indices textuels et archéologiques sont fragiles, il est possible d'émettre l'hypothèse de la présence d'un réduit fortifié dans le secteur oriental de la ville, à la fois constitué des murs du castrum existants, et de nouveaux murs maçonnés édifiés intra-muros et au niveau du chevet de la cathédrale (fig. 6). Dans tous les cas, toujours d'après la Chronique, dès 919, cette fortification est ruinée lors d'une nouvelle attaque des Scandinaves: "Si assaillirent lesdits Normans la cité de Nantes qui n'avoit en ce temps nul deffenseur, sinon petits hommes demourez des premières pestilences, et la prindrent fors le chasteau, qui pour la peur d'eux avoit esté faict, anquel tous les citoïens fuirent, fors ceux qu'ils avoient jà prins ou occis, afin qu'ils se peussent mieux deffendre; [...] Et les Normans au matin descendirent de leur nefs armez et retournèrent au chasteau; mais ils n'y trouvèrent rien. Si entrèrent en l'église et emportèrent à leur nefs les despoïlles et les ornements qui y estoient demeurez; puis mirent le feu en la couverture de l'église et la bruslèrent, et aussi dérompirent les murs du chasteau. " (Merlet, 1896, p. 84-85).

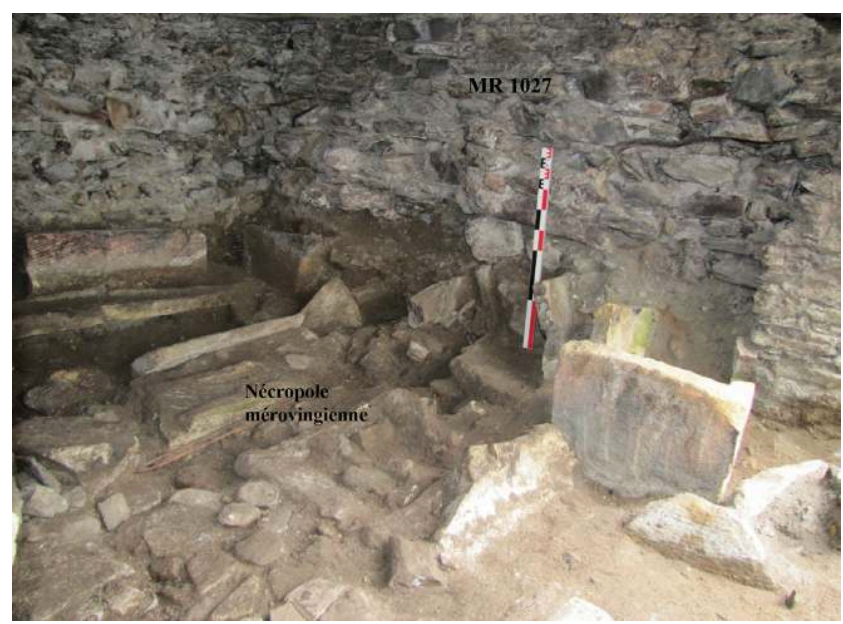

Figure 5 : Vue générale du mur MR1027, édifié sur des sarcophages de la période mérovingienne, et réemployé dans les fondations de la porte Saint-Pierre reconstruite au $\mathrm{Xv}^{\mathrm{e}}$ siècle (cliché DPARC).

Figure 5: Photography of the wall MR1027.

\section{LES FORTIFICATIONS D'ALAIN BARBETORTE À GUY DE THOUARS : DES OUVRAGES DÉFEN- SIFS MULTIPLES ET VARIÉS (XE SIÈCLE-DÉBUT XIIIE SIÈCLE)}

\section{Le " terrare " et la «turris principalis" d'Alain Barbetorte}

La domination des Scandinaves sur la région nantaise, qu'ils contrôlent vraisemblablement depuis des camps permanents installés sur les îles de la Loire ${ }^{11}$, prend fin vers 936 937, lorsque le futur " duc des Bretons ", Alain Barbetorte remporte une bataille engagée sur le "pré Sainct-Aignan " (Merlet, 1869, p. 90), situé sur de la prairie de Mauves, en face du faubourg de Richebourg (Guillotel, 2014, p. 484), ou sur la rive droite de l'Erdre, sur les premières pentes du Sillon de Bretagne (Guillaume, 2013, p. 89). Après cette victoire, la Chronique de Nantes indique que le chef breton s'installe à Nantes, au niveau de l'ancienne fortification de l'évêque Foucher, qu'il fait reconstruire : «il [Alain Barbetorte] leur commanda quils fissent un grand terrare ${ }^{12}$ au circuit de l'église, comme le mur du premier chasteau avoit esté, lequel accomply, il refist la tour principale et constitua sa maison dedans" (Merlet, 1896, p. 92-93). Les travaux semblent d'abord concerner l'enceinte construite autour du quartier

11. Peut-être depuis Saint-Florent-le-Vieil (île Batailleuse), ou depuis des îles près de Nantes (îles Grande-Biesse ou Petite-Biesse, ou encore île Boty), si l'on suit le toponyme "Bieta " indiqué dans la Chronique de Nantes.

12. "terrarium magnum " dans le texte en latin. 


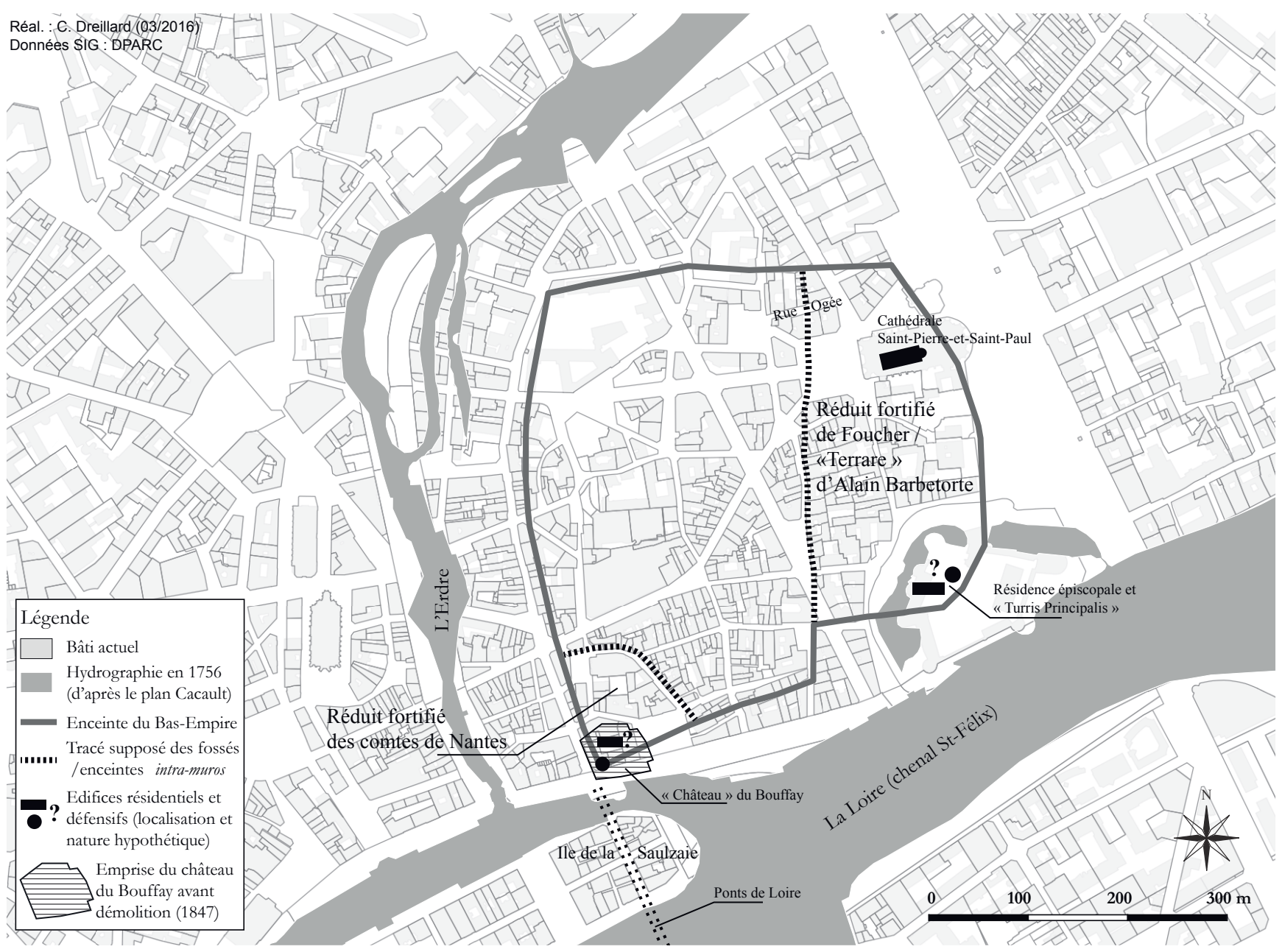

Figure 6 : Proposition de restitution des fortifications des $\mathrm{x}^{\mathrm{e}}-\mathrm{XI}^{\mathrm{e}}$ siècles (réal. : C. Dreillard; données SIG : DPARC). Figure 6: Urban fortifications during $10^{\text {th }}$ and $11^{\text {th }}$ centuries.

épiscopal, puisqu'un «terrare» - une probable levée de terre complétée d'un fossé - est aménagé en suivant le tracé des murs élevés quelques années auparavant pour protéger la cathédrale. Des vestiges correspondant peut-être à cet aménagement défensif du $\mathrm{x}^{\mathrm{e}}$ siècle ont récemment été observés au niveau de la rue Ogée (Le Boulaire, 2016) (fig. 6). En effet, un important creusement (fig. 7), d'une largeur estimée à une douzaine de mètres pour une profondeur d'au moins cinq mètres, $\mathrm{y}$ a été mis au jour en parallèle d'une section de rue antique traversant la cité du nord au sud. Bien que ne comportant aucun mobilier datant dans ses remblais de comblement, ce fossé, stratigraphiquement postérieur à des vestiges de l'Antiquité tardive et antérieur au $\mathrm{Xv}^{\mathrm{e}}$ siècle, pourrait donc être celui creusé lors de l'aménagement du "grand terrare ". Les travaux attribués au duc Alain par la Chronique concernent également la "tour principale» ("turris prinicipalis") de ce secteur fortifié, qui est réédifiée, ou réaménagée, de façon à en faire un espace résidentiel. Cette
" turris principalis» est occupée par les comtes de Nantes qui succèdent à Alain Barbetorte, puis devient résidence épiscopale à la fin du $\mathrm{x}^{\mathrm{e}}$ siècle : " il [Conan le Tors] vint à la cité de Nantes avecques grant exercice et print le chastel où le duc Allain Barbetorte et ses deux filz Hoel et Guérech, successivement comtes de Nantes avoient habité. Lequel chastel Conan commist et bailla en garde à Auriscandus, l'évesque de Vannes " (Merlet, 1896, p. 127). Un acte ducal de 1372 (Jones, 1980-1983, p. 538-539, acte n ${ }^{\circ}$ 925) permet de préciser la localisation de cet édifice. En effet, celui-ci indique que le château ducal de la Tour-Neuve a été construit à l'emplacement de l'ancien " manoir »/ « maison " épiscopal, déplacé à cette occasion à proximité la cathédrale. La "turris principalis" restaurée par Alain Barbetorte devait donc se trouver à proximité de l'angle sud-est de l'enceinte antique, au niveau de l'actuel château des ducs de Bretagne, lui-même édifié en 1466 pour remplacer le vétuste château de la Tour-Neuve (fig. 6). Cette localisation reste cepen- 


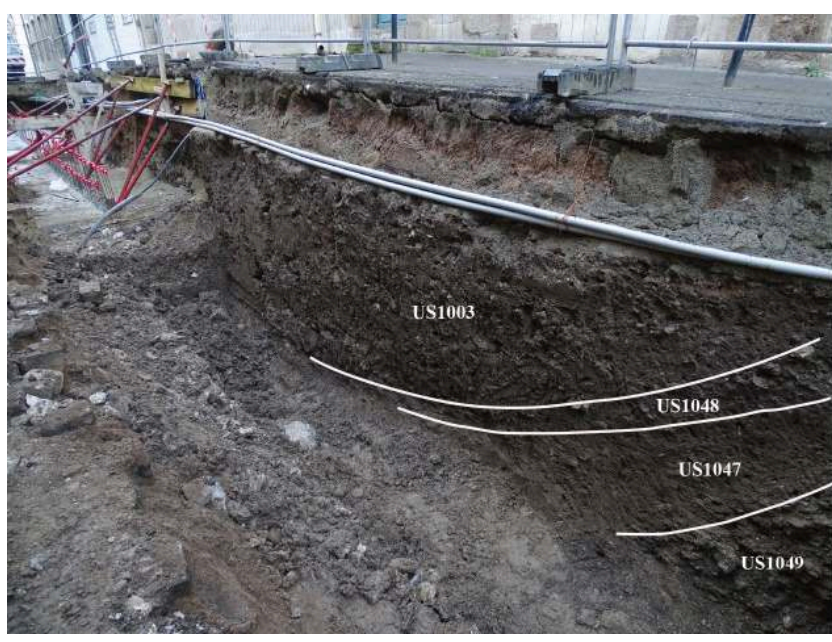

Figure 7 : Vue en coupe du fossé ( $\mathrm{x}^{\mathrm{e}}$ siècle?) mis au jour dans la rue Ogée (cliché C. Le Boulaire, DPARC).

Figure 7: Section of the ditch (10 th century?) discovered in Ogée street.

dant hypothétique et seulement basée sur l'interprétation de sources textuelles, aucun élément archéologique renvoyant à la "turris principalis" ou à la "maison" épiscopale n'ayant été mis au jour lors des campagnes archéologiques menées au château des ducs. Un dernier argument textuel, mis en évidence par M. Laurens-Berge (2014b, p. 24), vient étayer cette hypothèse : le château de la "Tour-Neuve " pourrait être dénommé ainsi par opposition à une "vieille tour", la «turris principalis » de l'ancienne résidence épiscopale et comtale.

\section{Le château du Bouffay}

Vers 990, le comte de Rennes Conan le Tors, alors en lutte avec le comte de Nantes pour le titre de duc de Bretagne, s'empare de la ville et fait édifier le château du Bouffay à l'angle sud-ouest du castrum : "et fist premierement, en l'anglet d'icelle cité vers la partie occindentelle jouste le fleuve de Laire, édiffier ung autre chasteau, lequel est maintenant appellé le Bouffay" (Merlet, 1896, p. 127-128). La construction de ce château est donc destinée à imposer l'autorité d'un nouveau seigneur sur la ville, comme en témoigne sa position stratégique lui permettant de contrôler et de surveiller l'accès nord de la ligne de ponts établie sur la Loire (fig. 6). Il convient d'ajouter que la mainmise du nouveau duc sur la ville se matérialise aussi par la nomination d'un nouvel évêque, qui s'installe dans l'ancienne résidence comtale (cf. supra). La forme originelle du château du Bouffay, qui reste le lieu de résidence nantais des ducs de Bretagne jusqu'au début du XIII ${ }^{\mathrm{e}}$ siècle, avant d'être utilisé comme prison, arsenal ou encore palais de justice, est difficilement perceptible. Si, à la suite de la Chronique de Nantes, la majorité des chroniqueurs et auteurs désignent l'édifice en employant le terme "forteresse ", qu'ils imaginent constituée d'une motte de terre et d'une tour de bois, d'autres indices textuels permettent plutôt d'émettre l'hypothèse d'une construction de type aulal capellal camera. En effet, plusieurs actes ducaux du $\mathrm{XI}^{\mathrm{e}}$ siècle indiquent avoir été rédigés et rendus à Nantes dans une aula et mentionnent également une chapelle (comtale?) située à proximité du château du Bouffay ${ }^{13}$. Ces mentions textuelles viennent étayer les remarques de M. Laurens-Berge (2014b, p. 19) qui évoquait la possibilité d'une construction associant une grande salle et un avant-corps ou une tour maçonnée, suivant le modèle des autres résidences comtales de la région (Tours, Angers, Le Mans). Il est également très probable que ces édifices aient été protégés par une enceinte castrale, dont le réseau viaire aurait figé l'emprise (fig. 6). Dans tous les cas, dès sa construction, ou au cours des siècles suivants, le château du Bouffay a en partie réemployé les murs de l'angle sud-ouest du castrum antique. Ainsi, lors de la démolition du château en 1847, les membres de la société archéologique nantaise identifient une " tour romaine " à l'angle sud-ouest de l'édifice. Cette tour dispose d'une chemise, "d'une ceinture ou enveloppe murale, ce qui faisait comme deux tours enchâssées l'une dans l'autre ", qui est "selon toute apparence [...] antérieure au $16^{\mathrm{e}}$ siècle" (Vandier, 1847, p. 19). Les documents iconographiques et planimétriques indiquent qu'au moment de sa démolition, le château du Bouffay accusait un plan quadrangulaire organisé autour d'une cour centrale et disposait d'au moins trois tours d'angles (Dreillard, 2014, p. 141-145) (fig. 8). Le château du Bouffay, aujourd'hui en partie situé sous un îlot d'habitation, n'a jamais été l'objet d'une campagne archéologique d'envergure, les opérations réalisées lors du réaménagement de la place éponyme et des allées attenantes en 2010 et 2011 n'ayant fait qu'effleurer l'ancienne emprise de l'édifice (Augry et al., 2014; LaurensBerge, 2014b).

\section{Un espace urbain intra-muros "bipolaire", et des faubourgs fortifiés? ( $\mathrm{XI}^{\mathrm{e}}-\mathrm{XII}^{\mathrm{e}}$ siècles)}

À la fin du $\mathrm{x}^{\mathrm{e}}$ siècle, deux pôles fortifiés sont donc constitués à l'intérieur du castrum antique, autour de la résidence comtale et ducale au sud-ouest, et autour de la résidence épiscopale et de la cathédrale dans le secteur est. Cette "bipolarité » de la ville intra-muros est la traduction topographique et physique de l'antagonisme qui oppose les seigneurs ecclésiastiques et laïcs nantais pendant toute la première moitié du XI ${ }^{\mathrm{e}}$ siècle (Laurens-Berge, 2015, p. 26).

13. "in aula mea Namnetis", "in capella juxta Bufetum ", "in aula videntibus istis Conano comite", "Nannetis postea in aula mea prorsus confirmavi (Guillotel 2014, p. 398, 418, 444, 517). 


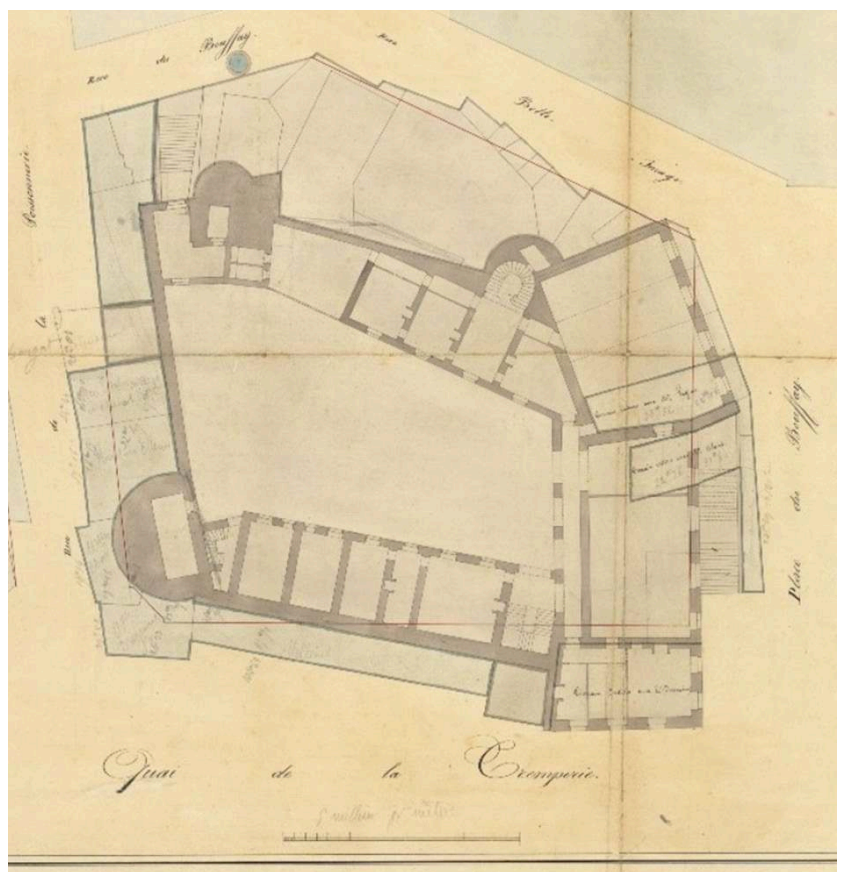

Figure 8 : Plan de l'ancien château du Bouffay (Archives départementales de Loire-Atlantique, 1N500).

Figure 8: Map of Bouffay castle.

En effet, ceux-ci sont alors régulièrement en conflit ouvert pour le contrôle de la ville, parfois même en lutte armée, notamment lorsque les évêques soutiennent la maison comtale de Rennes, en concurrence avec celle de Nantes pour le titre ducal (Tonnerre, 1994 : 287-295). Les deux pôles fortifiés jouent donc un rôle essentiel dans cette lutte de pouvoir : l'évêque de Nantes Gauthier fait ainsi augmenter et renforcer le «terrare » d'Alain Barbetorte, en y ajoutant une «maison fortifiée " : "Construxit enim ipse Walterius primum juxta parietes ecclesiae super terraculum, quod Alanus Barbatorta in circuiti proper metum Normannorum fecerat, domum in praesido munitam" (Merlet, 1896, p. 136). Cet édifice est détruit quelques années plus tard par le comte Budic : "Primum enim omnem domum episcopi aggreditur et diruit.» (ibid., p. 138).

Il convient par ailleurs de noter que le mur du castrum antique constitue encore un important marqueur topographique urbain aux $\mathrm{XI}^{\mathrm{e}}$-XII ${ }^{\mathrm{e}}$ siècles. En effet, pour cette période, de nombreux actes ducaux ont pour objet des donations faites à des groupes ecclésiastiques, dans lesquels les biens et propriétés concernés sont localisés en fonction $\mathrm{du}$ " mur de ville» (" murum civitatis»), qui délimite clairement un espace intra-muros et un espace extra-muros, répondant peut-être à des réalités juridiques, économiques et sociales différentes. L'étude de ces actes ducaux et du parcellaire ancien indique également que des enceintes privatives sont élevées dans les faubourgs de la ville dans le courant du XII ${ }^{\mathrm{e}}$ siècle. Ces dernières sont édifiées à l'initiative et autour d'établissements ecclésiastiques, avec l'accord de l'autorité ducale (fig. 9). Ainsi, au niveau du faubourg du Bourg-Main, sur la rive droite de l'Erdre, les Templiers ont élevés une " clôture " (" clausuram ») enserrant leur chapelle Sainte-Catherine, leur cimetière, ainsi que leurs " maisons " (Lemeillat, 2013, p. 113-115, acte $\mathrm{n}^{\circ}$ 50). Un peu plus au nord du Bourg-Main, c'est l'église Saint-Nicolas et le cimetière attenant qui devaient être ceints d'une protection, dont l'emprise a peut-être été figée dans la trame parcellaire. Il est aussi envisageable que d'autres « enclos » religieux aient existé autour des anciennes basiliques périurbaines comme Saint-Similien, plus au nord, et Saint-Donatien (hors plan), ou encore au niveau de l'église Saint-Clément, bien qu'aucune source n'en signale la présence. Il conviendrait également de s'interroger plus en détail sur l'éventuelle constitution d'un quartier canonial proche de la cathédrale (Laurens-Berge, 2015, p. 24, 26), question qui est inévitablement liée à celle de la durée et de la pérennité des fortifications épiscopales des $\mathrm{X}^{\mathrm{e}}-\mathrm{XI}^{\mathrm{e}}$ siècles. La nature et la forme de toutes ces enceintes restent évidemment hypothétiques en l'absence de données archéologiques.

\section{Les travaux de fortifications de Geoffroy II et Guy de Thouars (1185-1207)}

Plusieurs indices textuels permettent de supposer que des travaux de fortifications ont eu lieu au tournant du XII ${ }^{e}$ et du $\mathrm{XIII}^{\mathrm{e}}$ siècle sous l'impulsion du duc de Bretagne Geoffroy II et du baillistre (régent) Guy de Thouars. En effet, en 11851186, Geoffroy II verse une indemnité à la communauté ecclésiastique de Saint-Cyr, en dédommagement de fossés et de murs ("fosetis et muris") aménagés sur leurs propriétés, dans le faubourg établi entre le front nord de l'enceinte antique et l'Erdre (La Borderie, 1888, p. 117-118, acte $\mathrm{n}^{\circ}$ LIX; Everard et Jones, 1999, p. 30, acte ${ }^{\circ}$ Ge28). Ces aménagements renvoient peut-être à une campagne de fortification qui aurait eu pour but de prolonger le mur est du castrum jusqu'à la rivière, voire même d'inclure tout le faubourg dans une nouvelle fortification (fig. 9). D'après N.-Y. Tonnerre (1994, p. 529), ce quartier abrite en effet plusieurs ressources économiques importantes pour la ville, telles que des vignes et des moulins. Mais ces travaux de fortification ont surtout pu être motivés par le contexte politique, car à partir de 1183, Geoffroy II Plantagenêt est en conflit ouvert avec son frère Richard (alors duc d'Aquitaine et comte de Poitou) pour le contrôle de l'Anjou, et plus largement pour la succession sur le trône d'Angleterre et l'héritage de l'Empire Plantagenêt (Chedeville et Tonnerre, 1997, p. 93). 


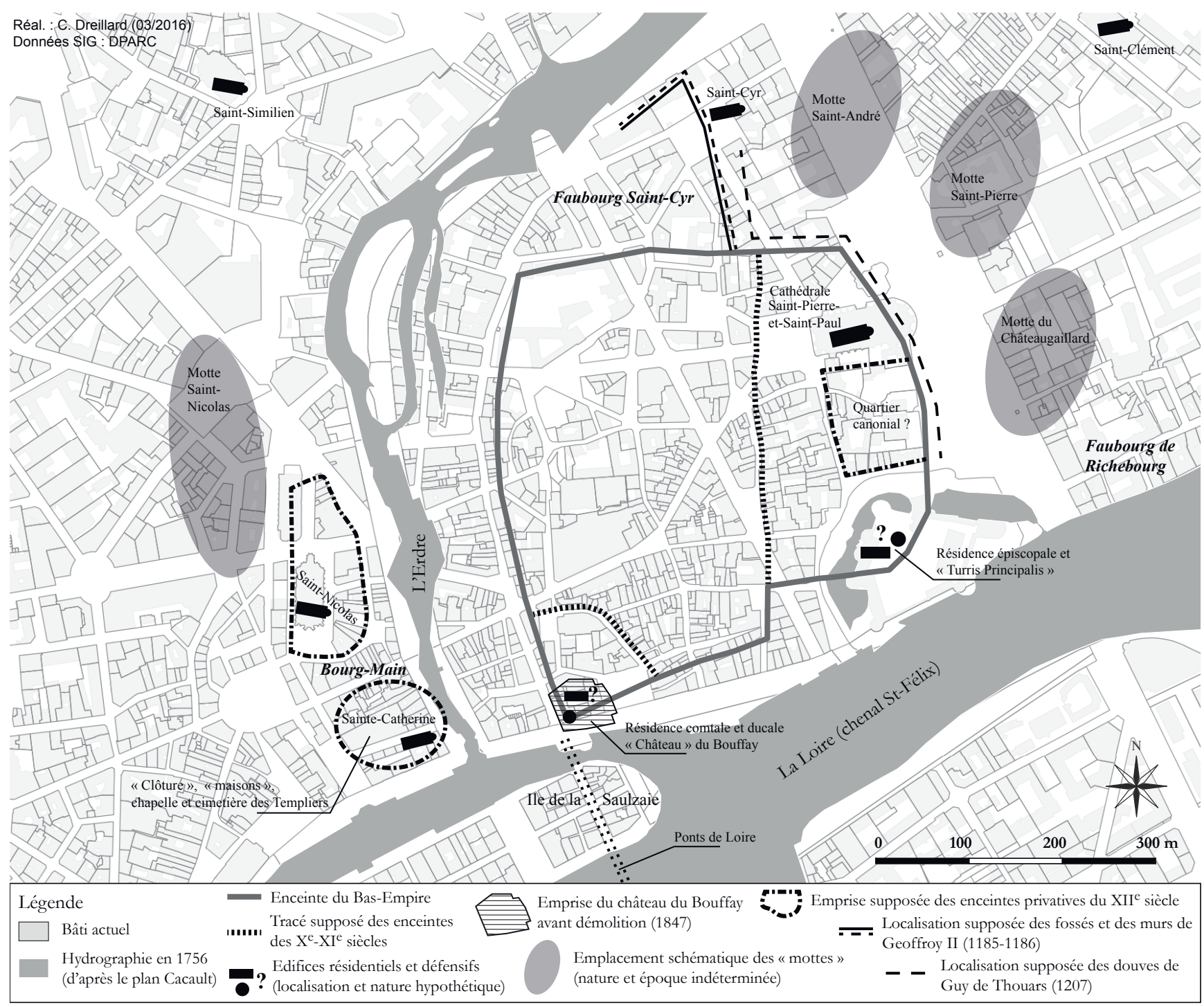

Figure 9 : Proposition de restitution des fortifications au début du XIII ${ }^{\mathrm{e}}$ siècle (réal. : C. Dreillard; données SIG : DPARC). Figure 9: Urban fortifications at the beginning of the $13^{\text {th }}$ century.

À la mort de Geoffroy II en 1186, puis de son fils Arthur I ${ }^{\text {er }}$, assassiné par Jean Sans Terre en 1203, la duchesse Constance, soutenue par la noblesse bretonne, noue une alliance avec le roi de France Philippe Auguste et épouse un de ces vassaux, le seigneur poitevin Guy de Thouars. Ce dernier prend alors les rênes du duché qu'il dirige en tant que "baillistre", au nom de sa femme, puis de sa fille mineure Alix de Bretagne. Guy de Thouars ne doit cependant sa fonction qu’à la volonté du roi de France, qui peut la lui retirer à tout moment s'il vient à manquer à ses obligations. C'est notamment le cas en 1206-1207, à un moment où Philippe Auguste craint un ralliement des nobles bretons au royaume d'Angleterre (ibid., p. 103). Le roi tient alors temporairement le duché en main propre et fait une entrée solennelle à Nantes. Toutefois, Guy de Thouars reste fidèle au roi, et retrouve rapidement sa fonction. C'est dans ce contexte d'opposition entre le royaume de France et d'Angleterre que Guy de Thouars fait réaliser quelques travaux de fortifications, attestés par deux actes ducaux. Le premier acte, une charte datée de l'année 1207 recopiée dans un vidimus de 1260, est la " preuve " régulièrement avancée depuis l'abbé Travers (1836, vol. 1, p. 307) faisant de Guy de Thouars le fondateur du château de la Tour-Neuve. Cet acte ne relate pourtant que le creusement d'une douve sur le fief canonial, non localisée précisément : "pro doha illa que facta est in feodo Canonicorum " (Everard et Jones, 1999 : 152-153, acte $n^{\circ}$ Gu14). Le château de la Tour-Neuve n'y est en aucun cas mentionné. Le second acte, une charte originale datée d'octobre 1207, se fait quant à lui beaucoup plus précis sur l'emplacement et la nature des travaux réali- 
sés par le baillistre : il signale ainsi qu'une douve est également aménagée sur des terrains appartenant aux chanoines, en avant d'un mur d'enceinte déjà existant, "du côté de Saint-Clément ": "ad recompensacionem dampnorum que Canonici Nannetensis [...] dohe que facta est extra muros versus Sanctum Clementem " (La Borderie, 1888, p. 140143, acte ${ }^{\circ}$ LXXIV; Everard et Jones, 1999, p. 152, acte $\left.\mathrm{n}^{\circ} \mathrm{Gu} 13\right)$. Le fossé creusé par Guy de Thouars est donc situé sur le front est, le long de l'enceinte du castrum antique, voire à proximité des murs établis dans le même secteur par Geoffroy II en 1185 (fig. 9). Il est toutefois difficile de déterminer si ces deux actes parlent d'un seul et même fossé, ou de deux fossés distincts. Néanmoins, l'existence de plusieurs chartes d'indemnisation aux montants différents pourrait induire l'existence de plusieurs fossés (ou d'un fossé réalisé en plusieurs phases), qui sont peut-être les témoins d'une vaste campagne de fortification urbaine. Dans tous les cas, la relecture de ces deux actes met en évidence l'absence d'indices concernant une éventuelle construction du château de la Tour-Neuve par Guy de Thouars, dont les aménagements renvoient plutôt à une campagne de fortification de la ville, notamment par la création de douves sur le front est. Il convient de préciser que cette démonstration sur l'origine du château de la Tour-Neuve a été effectuée et publiée à deux reprises par A. de La Borderie dès la fin du XIX ${ }^{e}$ siècle (La Borderie, 1885, p. 312-317; 1888, p. 140-143). Elle a cependant étrangement été " oubliée " par l'historiographie locale, et n'a été de nouveau prise en considération que très récemment (Laurens-Berge, 2014b, p. 22-28; Pascal, 2016, p. 62; Hayot, 2016, p. 92). Entre-temps, la très grande majorité des études historiques et archéologiques ont placé le début de la construction du château de la Tour-Neuve sous la régence de Guy de Thouars, en 1207, un an après la venue de Philippe Auguste à Nantes. Une datation plus tardive peut néanmoins être avancée à partir des sources textuelles disponibles pour le XIII ${ }^{\mathrm{e}}$ siècle (cf. infra).

\section{La question des mottes périurbaines}

Afin d'être complet sur l'évolution des fortifications de la ville du $\mathrm{x}^{\mathrm{e}}$ siècle au début du XIII ${ }^{\mathrm{e}}$ siècle, il convient de s'attarder sur la question des mottes périurbaines. En effet, quatre " mottes " sont attestées à Nantes : trois sont situées sur le front est (les mottes Saint-André, Saint-Pierre, du Châteaugaillard), tandis que la quatrième est localisée sur le front ouest (la motte Saint-Nicolas) (fig. 9). Ces mottes apparaissent dans les sources textuelles et les documents planimétriques à partir du Xve siècle. Elles sont cependant antérieures à cette époque, puisque les documents les mentionnant relatent les travaux d'aplanissement qui y sont faits. Ainsi, en 1424, c'est la " mote de terre " du "Chasteangaillart", située entre le faubourg de Richebourg et la douve protégeant l'angle sudest de l'enceinte urbaine, qui est nivelée pour la sécurité de la ville, afin d'empêcher l'artillerie ennemie de profiter de cette situation de hauteur (Blanchard, 1889-1895, vol. 3, p. 125126 , acte $\mathrm{n}^{\circ} 1585$ ). La motte Saint-Nicolas sert quant à elle de carrière de pierre en 1466 (AMN CC 247), tandis que les mottes Saint-André et Saint-Pierre disparaissent définitivement lors de la création des cours de promenades éponymes au XVIII ${ }^{\mathrm{e}}$ siècle. S'il est possible que ces « mottes » ne désignent en réalité que les hauteurs naturelles environnant la ville (les coteaux du Sillon de Bretagne et la ligne de crête entre la Loire et l'Erdre), il ne peut pas non plus être totalement exclu qu'elles puissent correspondre à des aménagements d'origine anthropiques, qui auraient été aménagées pour protéger les différents accès de la ville, comme le suggère le toponyme "Chasteangaillard». Si l'on retient cette dernière hypothèse, il faut alors s'interroger sur leur période de construction. Si elles sont donc nécessairement antérieures au $\mathrm{Xv}^{\mathrm{e}}$ siècle, on peut également supposer que la création de ces mottes est antérieure au perfectionnement et à l'utilisation plus fréquente de l'artillerie mécanique aux $\mathrm{XII}^{\mathrm{e}}$-XIII ${ }^{\mathrm{e}}$ siècles, puisque la prise de ces dernières par des ennemis aurait mis la ville intra-muros a portée de tirs des engins de siège type trébuchet ou couillard, dont la puissance aurait été décuplée par ces positions de hauteur. Les mottes pourraient par exemple avoir été édifiées dans le courant du XI ${ }^{\mathrm{e}}$ siècle, à l'instar de la campagne de fortification périurbaine constituée de mottes multiples attestée à Rennes pour cette période (Martineau et Schmitt, 2008, p. 27-29). Il est aussi possible que les mottes aient été constituées des déblais provenant du creusement des fossés du front est sous Geoffroy II et Guy de Thouars, comme le suggère l'un des textes : «la terre quion tirera de la douve pourra être rejetée soit sur le chemin, soit sur les autres terrains situés audelà du bord de la douve" (La Borderie, 1885, p. 316-317). La datation et la nature des « mottes " périurbaines restent donc incertaines, et en l'état actuel des connaissances, l'hypothèse la plus vraisemblable est qu'il s'agit de collines naturelles, parfois augmentées par les déblais issus du creusement de fossés, et qui ont pu ponctuellement être complétées d'ouvrages défensifs installés sur ces positions de hauteur.

\section{DES FORTIFICATIONS SYMBOLES DU POUVOIR DUCAL : Les CONSTRUCTIONS De Pierre de DreuX et Jean le Roux (XIIIE SIÈCle)}

\section{Une nouvelle enceinte urbaine}

Le ralliement de la noblesse bretonne au royaume de France plutôt qu'au royaume d'Angleterre au tout début du $\mathrm{XIII}^{\mathrm{e}}$ siècle entraîne l'arrivée d'un prince de sang capétien 
à la tête du duché de Bretagne. Ainsi, en 1213, Pierre de Dreux, cousin de Philippe-Auguste, épouse la duchesse Alix et succède à Guy de Thouars en tant que baillistre du duché, jusqu’à la majorité de son fils Jean I ${ }^{\text {er }}$ le Roux en 1237. S'il ne porte officiellement que le titre de baillistre, Pierre de Dreux agit bien dans les faits en tant que duc, et l'intégralité de son " règne » est marquée par sa volonté de renforcer le pouvoir ducal. Ainsi, il ne cesse de chercher à affaiblir l'épiscopat breton $^{14}$ (notamment nantais), tout en menant une politique d'extension et de fortification du domaine ducal, dans un premier temps destinée à imposer son autorité aux seigneurs bretons, puis, dans un second temps, pour s'affranchir de celle du roi de France (Leguay et Martin, 1997, p. 15-33). À Nantes, cette politique se traduit par la construction d'une grande enceinte urbaine de "réunion ", qui met fin à la pluralité des réduits défensifs intra et extra-muros des $\mathrm{X}^{\mathrm{e}}$ $\mathrm{XII}^{\mathrm{e}}$ siècles, symboles des pouvoirs concurrents dans la cité. La nouvelle enceinte urbaine englobe ainsi les faubourgs du Bourg-Main et de Saint-Léonard (fig. 10), tout en étant installée sur plusieurs propriétés de l'évêché, exproprié pour impératifs défensifs. Si les travaux de fortifications de Pierre de Dreux sont souvent relatés par l'historiographie nantaise dans le cadre du conflit opposant le baillistre à l'épiscopat nantais et breton, le réexamen des sources textuelles de première main y faisant allusion permet tout de même de préciser la nature et la chronologie de mise en œuvre de ces réalisations.

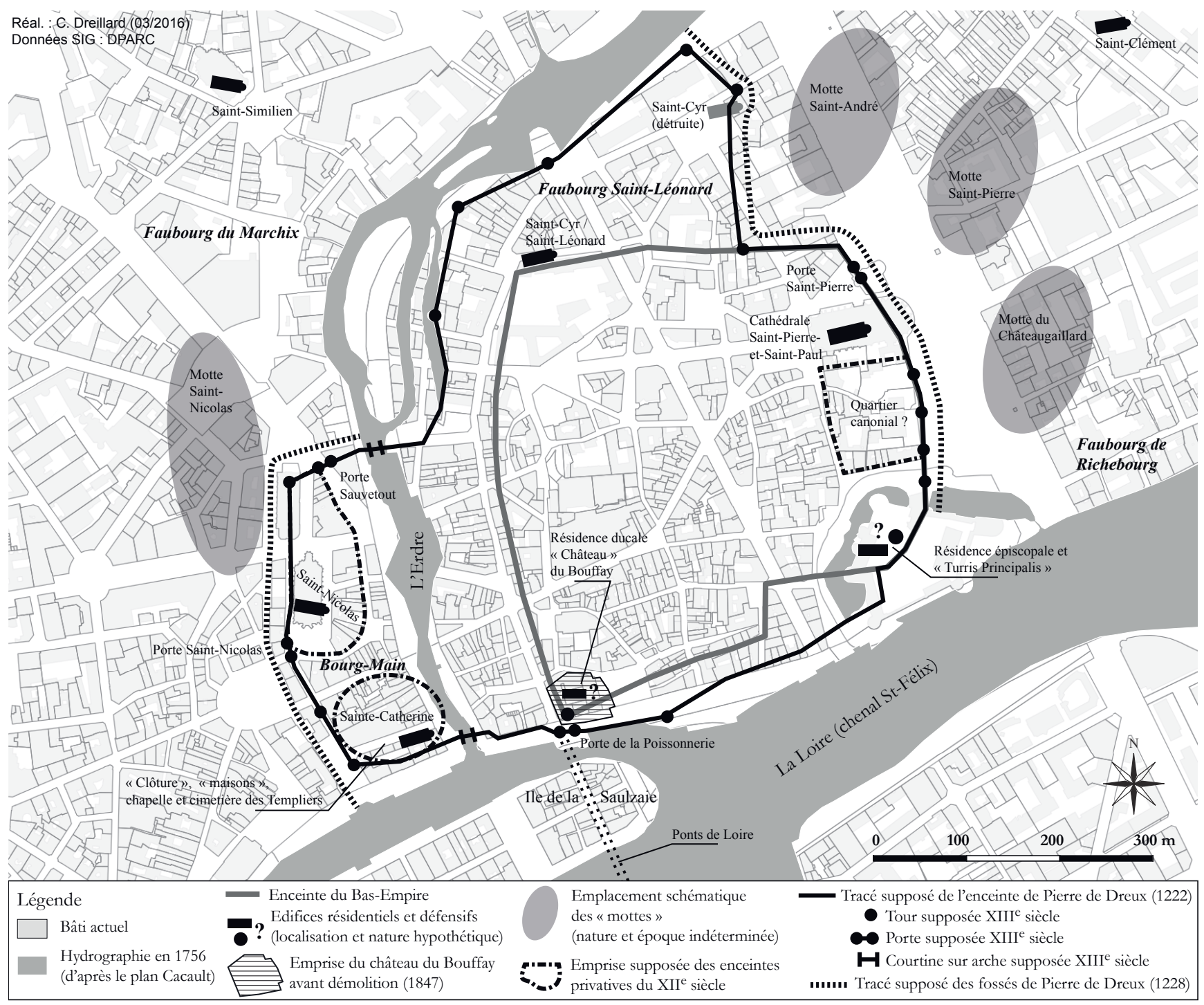

14. Ce qui lui vaut d'être l'objet de plusieurs sentences d'excommunications et lui fait par ailleurs gagner son surnom de « Mauclerc ».
Figure 10 : Proposition de restitution des fortifications en 1228 (réal. : C. Dreillard; données SIG : DPARC).

Figure 10: Urban fortifications in 1228. 
Ainsi, les premiers travaux signalés concernent l'aménagement de fossés sur des terres appartenant à l'évêque avant l'année 1218, peut-être au niveau du faubourg du Marchix, situé sur la rive droite de l'Erdre, qui a aussi été incendié (Lemeillat, 2013, p. 94-99, acte $\left.\mathrm{n}^{0} 39\right)^{15}$. En 1222, la construction des murs d'enceinte semble achevée, puisqu'un acte ducal signale explicitement que des murs ont été construits autour de la ville pour « cause de guerre ${ }^{16} »:$ « $[\ldots]$ cum civitatem Nannetensem, propter guerras, muris cingi fecerimus $[\ldots] »\left(\right.$ Lemeillat, 2013, p. 113-115, acte $\mathrm{n}^{\circ}$ 50). Cet acte mentionne également des travaux effectués sur une portion précise de l'enceinte, au niveau de son angle sudouest, dans le faubourg du Bourg-Main, à l'endroit où, au siècle précédent, les Templiers ont édifié leur " clôture " pour protéger leur " maison» et leur cimetière : «[...] murum qui claudit burgum Main clausuram fratrum militiae Templi, quam circa domos suas et cimeterium fecerant attinxit [...]". Cette " clôture " a été réemployée en soubassement de la " nouvelle » enceinte urbaine : " [...] unde super eamdem clausuram apposuimus opus novum [...] ", elle-même flanquée et constituée d'ouvrages défensifs de nature diverse : "[...] et construi ibidem fecimus propugnacula [remparts?], turriculas [tourelles?] et alias munitiones [fortifications?] ». Au-delà de leur appartenance au champ lexical des fortifications, il semble assez hasardeux de tirer des conclusions sur la nature réelle des ouvrages désignés par ces trois termes. La suite de l'acte règle le problème de la propriété et de l'entretien de cette nouvelle section de l'enceinte urbaine, qui réemploie donc une partie de l'enceinte des Templiers. Ces derniers restent propriétaires des murs élevés et exhaussés par le baillistre sur leurs terres, mais en sont déchargés de tout entretien (ibid., p. 114).

Les fortifications de la ville sont encore en cours d'aménagement autour de l'année 1228. En effet, à l'occasion d'une charte d'indemnisation accordée au chapitre de Nantes, Pierre de Dreux indique qu'il a fait faire des "fortifications " ( "munitiones») et des fossés ("fossata») autour des murs de la ville précédemment élevés (Lemeillat, 2013, p. 140-141, acte $\mathrm{n}^{\circ}$ 63). De nouveau, il est difficile de déterminer à quels types d'ouvrages renvoient ces "munitiones» appartenant au dispositif défensif avancé de la ville, au même titre que les fossés. L'aménagement des fossés et de « barbacanes » dans

15. "Au sujet de l'incendie du bourg du Marchix, de la destruction de maisons à cause de l'aménagement de fossés sur la terre de l'évêque, de l'occupation de la terre [...] au sujet de quoi il y avait contentieux entre l'évếque et le comte, l'évêque les fait à son tour respecter, pour le bien de la paix. "

16. Le risque de guerre en question renvoit peut-être à la révolte des grands nobles bretons contre l'autorité et la politique de Pierre de Dreux, qui se conclue par une bataille rangée près de Châteaubriant en mars 1222 (Coativy, 2008 : 89-101). Il faut aussi noter que de 1223 à 1234, Pierre de Dreux participe à plusieurs révoltes armées contre l'autorité royale (Leguay et Martin, 1997, p. 31-32). le secteur nord-est de la ville entraîne par ailleurs la destruction de l'église Saint-Cyr ${ }^{17}$ et d'une partie de son cimetière paroissial, comme en témoigne une sentence arbitrale d'un légat du Pape de l'année 1248, qui relate les « exactions » de Pierre de Dreux et son fils Jean le Roux contre l'épiscopat nantais, publiée par Dom Morice (1742-1746, p. 936) : "Fecit in super idem comes fieri fossata et barbacanas circa civitatem in terra Ecclesie Nannet. Et pro fossatis faciendis diruit domos hominum Ecclesie, et fecit omnino destrui ecclesiam S. Cyrici parochialem, exhumatis corporibus de cimeterio, in qua ecclesia erant moniales"

Les fortifications de Pierre de Dreux n'ont pas laissé de traces archéologiques véritablement attestées. En effet, les murs et fossés du XIII ${ }^{e}$ siècle ont généralement disparu lors de la reconstruction de l'enceinte urbaine $\mathrm{au} \mathrm{Xv}^{\mathrm{e}}$ siècle. Les rares vestiges antérieurs à ces fortifications adaptées à l'artillerie à poudre qui ont été mis au jour lors de campagnes archéologiques sont seulement supposés correspondre aux réalisations du baillistre du début du XiII ${ }^{\mathrm{e}}$ siècle. Au niveau de la porte Sauvetout, il faut ainsi noter la présence d'une courtine et d'un fossé antérieurs au réaménagement de la porte à la fin du Xve siècle (Guérin, 1995; Martineau, 2001; Lacoste, 2012). Sur le front est, le réemploi de l'enceinte antique dans une nouvelle courtine médiévale, elle-même réaménagée à la fin du $\mathrm{Xv}^{\mathrm{e}}$ siècle est attesté, mais la chronologie fine de ces différents aménagements reste hypothétique (Pacaud, 2010). Enfin, sur le front sud, l'emprise des sondages archéologiques n'a pas permis d'atteindre les niveaux stratigraphiques correspondant aux états de fortifications du XIII ${ }^{\mathrm{e}}$ siècle (Augry et al., 2014; Laurens-Berge, 2014a; 2014b).

À partir de ces quelques indices textuels et archéologiques, il est tout même possible de déterminer la nature des aménagements de Pierre de Dreux. Ceux-ci consistent donc en la construction d'une enceinte maçonnée, complétée de fossés défensifs ${ }^{18}$, mais également d'ouvrages avancés, de type barbacane, qui restent mal localisés. L’enceinte maçonnée n'est pas intégralement construite ex nibilo, mais reprend en partie certains éléments des fortifications antérieures. C'est notamment le cas sur le front est, où la courtine antique est réemployée partiellement, ainsi qu'au niveau de l'angle des fronts sud et ouest, où c'est la «clôture » des Templiers qui est réutilisée et exhaussée (fig. 10). Un réemploi de l'enceinte de l'église Saint-Nicolas est aussi envisageable sur le front ouest. Les constructions de Pierre de Dreux viennent sans doute également compléter les fortifications établies à la fin du

17. Qui est ensuite reconstruite à proximité de l'angle nord-ouest de l'ancien mur d'enceinte antique, avant de prendre le vocable de SaintLéonard (Leguay et Martin, 1997, p. 47).

18. Il convient ici de rappeler que Pierre de Dreux est aussi à l'origine de l'aménagement de fossés défensifs dans la ville de Rennes (les « Fossés à Gahier») (Leguay et Martin, 1997, p. 20; Baudry, 2011, p. 179). 
$\mathrm{XII}^{\mathrm{e}}$ siècle et au début du XIII ${ }^{\mathrm{e}}$ siècle par Geoffroy II et Guy de Thouars. Ces dernières semblent d'ailleurs avoir déjà efficacement amélioré la capacité défensive de la ville, puisqu’à peine un an après l'arrivée au pouvoir de Pierre de Dreux (1213), elle résiste aux assauts des troupes du roi d'Angleterre Jean Sans Terre (Pocquet du Haut-Jussé, 1929, p. 141).

\section{Le château de la Tour-Neuve}

Sans revenir sur la question des travaux de fortifications de Guy de Thouars (cf. supra), il convient de noter qu'aucune allusion au château de la Tour-Neuve n'a été identifiée dans les actes publiés de Pierre de Dreux (Lemeillat, 2013) ce qui, en l'état actuel des connaissances archéologiques et historiques, laisse supposer que le château du Bouffay garde le statut de résidence ducale jusqu'à la fin de la régence du baillistre (1237). Les plus anciennes mentions textuelles du château de la Tour-Neuve sont présentes dans deux textes de 1248 et 1259, recopiés et publiés par le congréganiste mauriste Dom Morice (1742-1746, t. 1, p. 935-939; p. 972-973). Ces deux textes relatent, entre autres, les litiges opposant le duc Jean I ${ }^{e r}$ le Roux à l'évêché de Nantes, au rang desquels se trouve la construction du château ducal sur un terrain appartenant à l'évêché, situé à l'intérieur des murs de la ville: "fundum in quo situm est castrum quod dicitur Turris Nova infra muros civitatis ad ipsum Episcopum Nannet". Ce château semble constitué d'une " tour " et d'une " enceinte» (" turre cum clausura»). La construction de l'édifice est bien reprochée à Jean le Roux et non à son père Pierre de Dreux, auquel est seulement attribué l'aménagement des " fossés et barbacanes autour de la ville ". La construction du château de la Tour-Neuve doit donc vraisemblablement avoir eu lieu entre le début du règne de Jean le Roux et la rédaction des deux actes, à savoir dans la période 1237-1248, et non à partir de 1207, comme indiqué "traditionnellement ". Bien que cette datation ne "rajeunisse " l'édification du château de la Tour-Neuve que d'une quarantaine d'années au maximum, elle semble tout de même importante, car directement en lien avec les vestiges archéologiques attribués au château de la Tour-Neuve mis au jour sous la cour de l'actuel château des ducs de Bretagne (Stany-Gauthier, 1937; Pascal et al., 2007b). Ces campagnes de fouilles ont en effet révélé la présence d'une grosse tour cylindrique de $16,70 \mathrm{~m}$ de diamètre, adossée contre le parement interne du mur du castrum antique, à partir duquel se développe également une enceinte rectangulaire, probablement renforcée aux angles par des tours demi-circulaires (Pascal, 2014, p. 215, 221, Pascal 2016, p. 62-73) (fig. 11). Cette construction semble donc être inspirée du modèle architectural "philippien " élaboré par le roi de France Philippe-Auguste au début du siècle. Enfin, il convient de rappeler que les sources textuelles signalent que le château de la Tour-Neuve est édifié à l'emplacement de la résidence épiscopale, alors déplacée au nord de la cathédrale (cf. supra). Bien qu'aucune campagne archéologique n'ait atteint ces niveaux d'occupation, il est possible de supposer que le château de Jean le Roux ait pu réemployer une partie du palais édifié par les évêques nantais à partir du $\mathrm{x}^{\mathrm{e}}$ siècle. Outre son rôle de défense de l'angle sud-est de l'enceinte urbaine, le château de la Tour-Neuve, édifié selon un modèle royal et installé sur les terres de l'évêque, semble bien symboliser la politique de renforcement du pouvoir poursuivie par Jean le Roux, dans la lignée de celle de son père Pierre de Dreux (Leguay et Martin, 1997, p. 18-19; Lemeillat, 2014, p. 13-17).

\section{Le déclassement de l'enceinte antique}

La construction de l'enceinte de réunion sous Pierre de Dreux entraîne le déclassement du mur d'enceinte antique, si tant est qu'il jouait alors encore un réel rôle dans la défense de l'espace urbain nantais. Son abandon progressif et son " absorption " par le tissu urbain à partir du XIII ${ }^{\mathrm{e}}$ siècle sont dans tous les cas attestés par les sources textuelles et par l'archéologie. Ainsi, le mur d'enceinte est peu à peu cédé par le duc à divers propriétaires, notamment des ecclésiastiques, qui s'en servent pour installer leurs établissements. En 1246, Jean le Roux cède ainsi au prieuré de Saint-Cyr « des places, lieux et mur sarrasin ${ }^{19}$ afin d'y construire ou de consolider des édifices" situés près d'un lieu ou "les frères de l'ordre mineur $y$ bâtissent ou y feront bâtir ». Les frères mineurs mentionnés dans ce texte appartiennent à l'ordre mendiant franciscain des Cordeliers. Ces derniers ont en effet reçu de Jean le Roux des terrains situés de part et d'autre de l'ancien mur d'enceinte, qu'ils réemploient pour édifier le mur gouttereau de leur église Saint-Michel. Ce réemploi a permis la conservation en élévation d'une importante section du mur du castrum, qui a par ailleurs récemment fait l'objet d'une étude de bâti (Lallauret, 2015). Il convient d'ajouter que le déclassement du mur d'enceinte antique se fait de manière progressive, puisque des sections des "anciens murs" et de "lancienne clousture » de la ville sont encore cédées par le pouvoir ducal dans la seconde moitié du XIV ${ }^{e}$ siècle. Les Jacobins obtiennent ainsi des terrains situés entre le mur du castrum et la courtine sud de l'enceinte urbaine médiévale, non loin des portes Briant-Maillart et Drouin-Hilliart (Jones, 1980-1983, p. 101-102, acte n ${ }^{\circ} 44$; Jones, 1996,

19. L'expression "mur sarrasin» est fréquemment utilisée dans les textes médiévaux et pourrait être une déformation des " murs césarins " (césarin/cérasin/sarasin) désignant les constructions d'époque " antique ", à la manière des nombreux " camps de César " présents dans l'espace rural (Naulin, 1957, p. 133). 


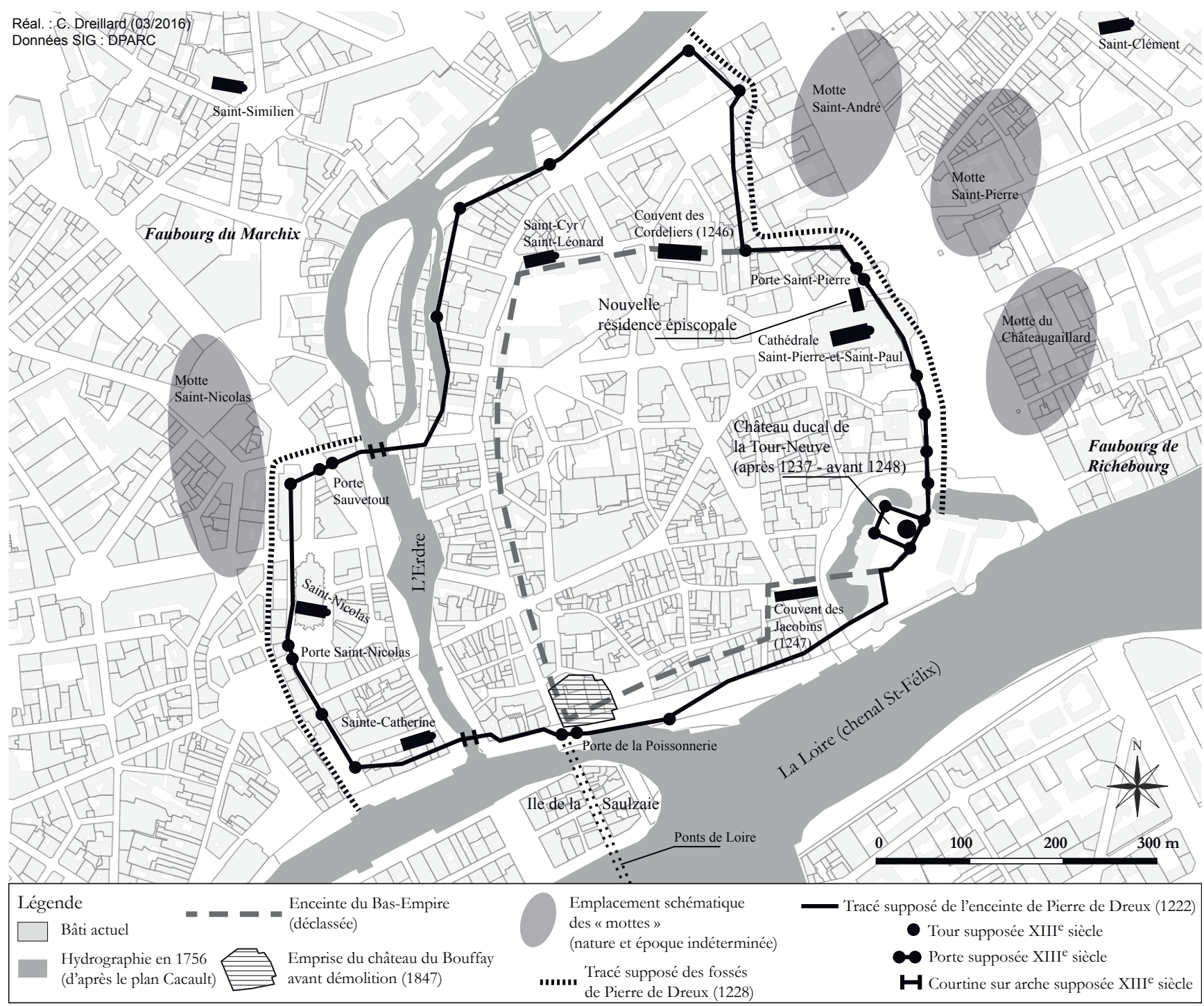

Figure 11 : Proposition de restitution des fortifications en 1248 (réal. : C. Dreillard; données SIG : DPARC).

Figure 11: Urban fortifications in 1248.

p. 181-182, acte $n^{\circ} 203$ ), tandis que les Carmes reçoivent la propriété d'une section du castrum située à proximité de l'Erdre (Jones, 1980-1983, p. 103, acte no 46).

\section{LES ForTifications de JEAN II À JEAN IV : DE SIMPLES TRAVAUX D'ENTRETIEN ET DE MISE EN DÉFENSE? (XIVE SIÈCLE)}

\section{Nantes pendant la guerre de Succession de Bretagne}

En l'état actuel des connaissances, aucun indice textuel ou archéologique ne permet d'attester d'éventuels travaux de fortifications à Nantes de la mort de Jean ${ }^{\text {er }}$ le Roux
(1287) à celle de Jean III (1341). D'un point de vue politique, les ducs régnant pendant cette période se conduisent en fidèles vassaux de la couronne de France, obtenant officiellement pour la Bretagne le statut de duché-pairie du royaume en 1297, et participant aux premières batailles de la guerre de Cent Ans aux côtés des troupes françaises (Leguay et Martin, 1997, p. 34). Cette période de stabilité du pouvoir ducal breton prend fin à la mort de Jean III, qui disparaît sans héritier ni successeur désigné. Son décès est suivi par une crise dynastique de vingt-trois années, pendant laquelle les différents protagonistes sont alternativement soutenus par les royaumes de France et d'Angleterre, eux-mêmes en conflit dans le cadre de la guerre de Cent Ans. La guerre de Succession de Bretagne doit être considérée comme une guerre civile, marquée par de nom- 
breuses trêves, trahisons et " coups de main ", au cours desquels les villes et places fortes changent régulièrement de camp. Nantes est ainsi prise par Charles de Blois et l'armée française à l'issue d'un siège de 15 jours en 1341 (ibid., p. 102). Si le conflit de succession affaiblit considérablement le pouvoir ducal, ce n'est pas le cas des communautés urbaines, qui, au contraire, gagnent en autonomie et commencent à se constituer en organisations municipales (ibid., p. 117). En effet pour se protéger, les villes lèvent leurs propres impôts, destinés à être employés aux travaux de fortifications. L'instauration de ces impositions municipales est connue par l'intermédiaire d'actes officiels, ratifiés par l'autorité ducale, qui donnent lieu à des descriptions précises des travaux devant être effectués grâce aux revenus levés. À Nantes, il semble que ces aménagements aient avant tout pris l'allure de travaux de mise en défense. Un acte de 1348 signale ainsi diverses réparations de l'enceinte urbaine, complétées par l'ajout de fortifications temporaires en matériaux périssables (des hourds et des guérites sur les murs du front nord), par le creusement de fossés autour de l'enceinte urbaine, par l'installation de palissades recouvertes de peaux, ainsi que par la construction de pièces d'artillerie mécanique : Item, pour la reparation de ladite ville, tant pour muys, engins, espingalles, hourdeis, garites, qui faillent devers Erdre, et ailleurs, fossez, clostures de paulx, et pour articlerie qui sera gardee selon lordonnance $d u$ capitaine et des bourgeois" (Jones, 1996' p. 105-107, acte $\mathrm{n}^{\circ}$ 98). Il faut aussi préciser que ces impôts servent également à financer la garnison permanente de la ville, composée d'une centaine d'hommes d'armes et d'arbalétriers.

\section{Les fortifications sous Jean IV : privilèges urbains, château de la Tour-Neuve et forteresse de Pirmil (1365-1399)}

La guerre de Succession prend fin en 1365 avec la signature du traité de Guérande, par lequel Jean IV est officiellement reconnu duc de Bretagne par les rois de France et d'Angleterre. Le rôle croissant des habitants de la ville (représentés par un conseil de bourgeois) dans l'entretien des fortifications est perceptible dans les actes produits par la chancellerie de Jean IV. En 1397, le duc accorde en effet officiellement à la ville certaines libertés dans la manière de lever les impôts qui doivent être " employez en la fortifficacion et reparacion de nostredite ville de Nantes et de nostre chastel de Piremil» (Jones, 1980-1983, p. 658-659, acte n ${ }^{\circ} 1107$ ). Le prolongement de ce privilège par la duchesse Jeanne de Navarre en 1402 est l'occasion d'en apprendre un peu plus sur l'état des fortifications: "notre ville avoit besoing et necessité de reparacion, et en estoient les guérites murs et cloaison d'icelle abutez cheois et despecez, en pluseurs lieux et endroiz, parce que lediffice estoit ancien et de si long temps, et avoit esté fait de si foible matere que ce estoit chose qui ne se povoit bonnement perpetuer ne soustenir ne l'estat ou elle estoit; et aussi par la fortune et violence de grans vents, et autrement, avoient este lesdictes guérites et cloaison affoiblyes et empirees " (La Nicollière-Teijeiro, 1883, p. 18-19, acte ${ }^{\circ} \mathrm{XI}$ ). De toute évidence, l'enceinte urbaine est en mauvais état. Cela ne paraît pas trop surprenant, puisqu'aucune campagne de travaux d'envergure ne semble attestée entre sa construction, au début du XIII ${ }^{\mathrm{e}}$ siècle, et ce début de $\mathrm{XV}^{\mathrm{e}}$ siècle, alors que la ville a dû subir entre-temps les affres du temps et du conflit de succession. Les privilèges accordés par le duc Jean IV et la duchesse Jeanne de Navarre aux bourgeois de la ville ont donc pour objectif d'encourager les travaux de réparation de l'enceinte urbaine.

Le château ducal de la Tour-Neuve est quant à lui peutêtre concerné par des travaux d'extension. Des sources textuelles présentées par A. de La Borderie (1991, p. 76-77) indiquent en effet que d'importantes sommes d'argent sont "emploier es ouvres de la Tour Neuve de Nantes" et qu'un terrain situé entre la douve du château et le cimetière des Jacobins est acquis par le duc. Ces mentions textuelles pourraient éventuellement correspondre à l'aménagement de l'enceinte flanquée de tours polygonales sur la pente naturelle des bords de Loire, à l'extérieur des anciens murs de l'enceinte antique, qui a partiellement été observée lors des fouilles effectuées dans la cour du château des ducs (Pascal et al., 2007b, p. 215; Pascal, 2016, p. 73-83) (fig. 12). Cette datation reste cependant hypothétique, puisque aucun mobilier datant significatif associé à ces structures n’a été mis au jour (Pascal et al., 2007b, p. 74). Les travaux effectués au château de la Tour-Neuve sous Jean IV sont aussi potentiellement motivés par une volonté précoce d'adaptation à l'artillerie à poudre, même si les textes n'attestent que de son utilisation par la garnison pour la défense de la forteresse ducale, au côté de l'artillerie mécanique (Jones, 1992, p. 163-172).

Les travaux de Jean IV en matière de fortification urbaine consistent aussi en la construction de la forteresse de Pirmil sur la rive sud de la Loire (fig. 13). Cet édifice a pour vocation de protéger, mais surtout de contrôler, l'accès aux ponts et la ville de Nantes. La ville avait en effet principalement soutenu le parti de Charles de Blois et Jeanne de Penthièvre pendant le conflit de succession, et Jean IV n'en reprend le contrôle qu'après la signature du traité de Guérande. Aucune source textuelle de première main ne permet toutefois de prouver la construction de la forteresse dès 1465 , comme indiqué par le chroniqueur breton Alain Bouchart (1986, t. 2, p. 97, XCIII), qui en attribue par ailleurs la mise en œuvre à l'un de ses ancêtres, l'amiral de Bretagne Nicolas Bouchart. Seule l'antériorité 


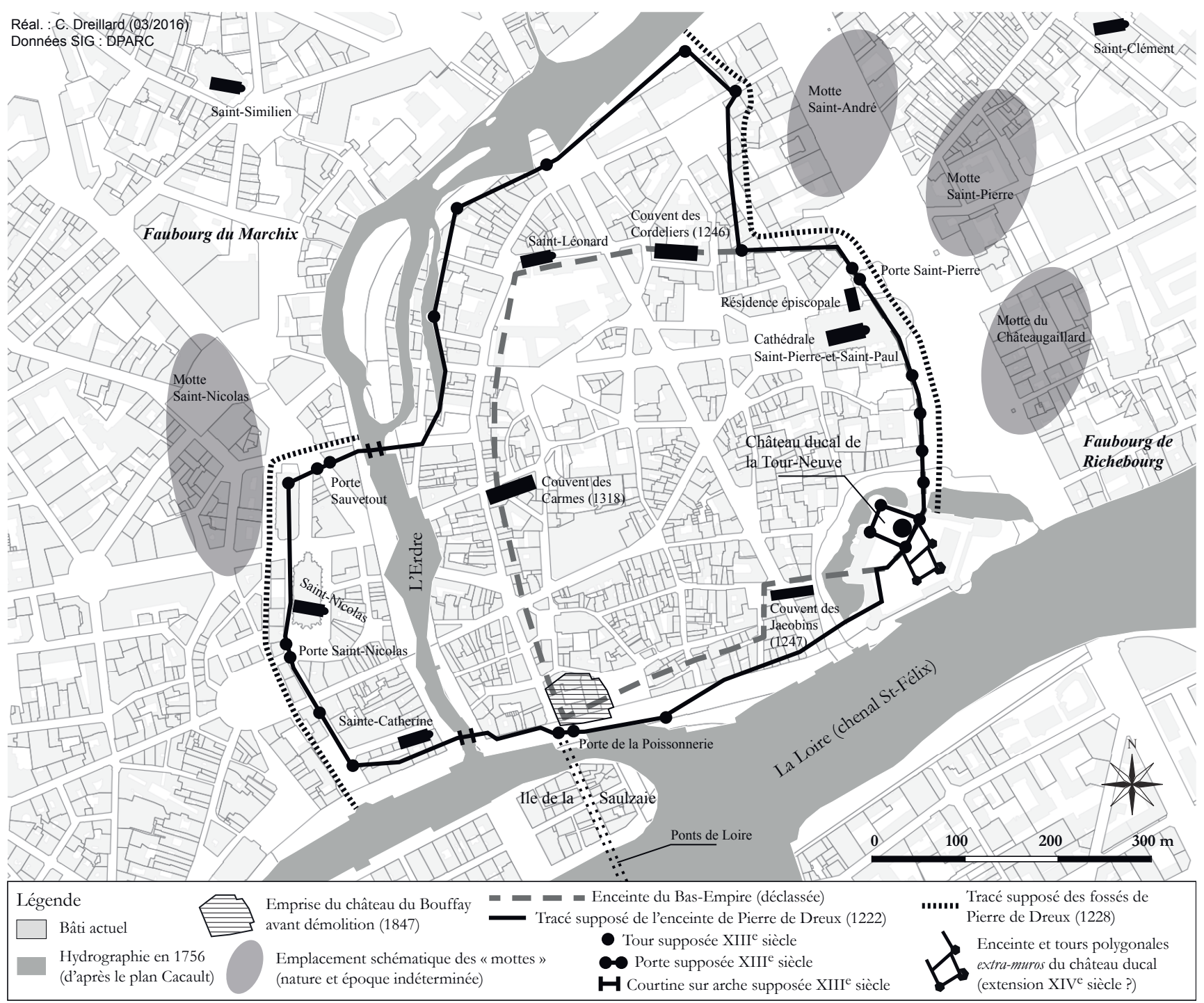

Figure 12 : Proposition de restitution des fortifications à la fin du XIVe siècle (réal. : C. Dreillard; données SIG : DPARC). Figure 12: Urban fortifications at the end of the $14^{\text {th }}$ century.

de la forteresse à l'année 1381 est attestée par les textes, qui y signalent par ailleurs d'importants travaux de réfection en 1397 et 1402 (Jones, 1980-1983, p. 312, acte $\mathrm{n}^{\circ} 378$; 658-659, acte $\mathrm{n}^{\circ} 1107$; La Nicollière-Teijeiro, 1883, p. 18 19 , acte $\mathrm{n}^{\circ} \mathrm{XI}$ ). Cette forteresse, qui est notamment commandée par une grosse tour circulaire (fig. 13 et 14), est démantelée officiellement en 1626 mais perdure toutefois dans le paysage nantais jusqu'au moment de sa démolition en 1839 (Bougouin, 1864 : non paginé). Elle est ainsi figurée sur de nombreux documents iconographiques et planimétriques représentant la ligne de ponts sur la Loire (Dreillard, 2014, vol. 1, p. 160-165; vol. 2, p. 71-78). À ce jour, aucune opération archéologique n’a jamais été réalisée sur l'ancienne emprise de l'édifice. Pour conclure sur les travaux de fortifications effectués au xIv ${ }^{e}$ siècle, il semble donc que ces derniers aient principalement pris la forme de travaux de mise en défense et de réparation de l'enceinte urbaine pendant la guerre civile, ensuite complétés après la victoire de Jean IV par de grands travaux de construction au château ducal et à la forteresse de Pirmil. 


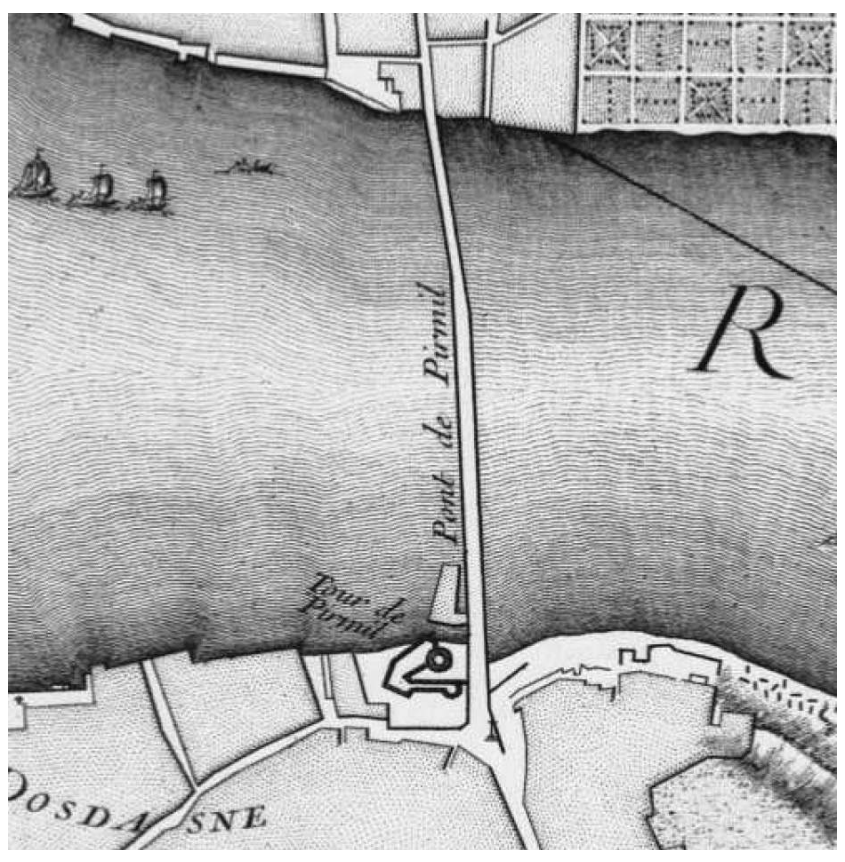

Figure 13: La forteresse de Pirmil sur le plan Cacault de 1756 (vue de détail) (Archives municipales de Nantes, II 157/6).

Figure 13: Pirmil fortress on the Calcault map in 1756.

\section{Les Fortifications de JEAN V}

À FranÇOIS II : UNE NOUVELLE ENCEINTE URBAINE ADAPTÉE À L'ARTILLERIE À POUDRE, AU CCEUR DE LA DÉFENSE DE « L'ÉTAT » BRETON $\left(\mathrm{XV}^{\mathrm{E}}\right.$ SIÈCLE $)$

\section{Les réalisations de Jean $\mathrm{V}$ : premières transformations d'un dispositif défensif vétuste (1399-1442)}

Le $\mathrm{Xv}^{\mathrm{e}}$ siècle breton est marqué par la mise en place d'un duché autonome, aux allures d'état indépendant du royaume de France. Dans la première moitié du siècle, le duc Jean $\mathrm{V}$ profite ainsi de la faiblesse de la monarchie française, déstabilisée par ses échecs répétés dans le cadre de la guerre de Cent Ans, pour développer librement tous les rouages d'un " état " moderne, en tenant la Bretagne à l'écart du conflit entre la France et l'Angleterre, et en pratiquant une politique de "neutralité opportuniste " (Leguay et Martin, 1997, p. 194). Cette politique lui permet de renforcer le pouvoir ducal, tout en assurant une certaine prospérité économique au duché, qui est épargné par les ravages de la guerre. Néanmoins, tout comme son prédécesseur Jean IV à la fin du siècle précédent, Jean $V$ est conscient du mauvais état et de la faible valeur défensive des fortifications urbaines héritées du début du XIII ${ }^{\text {e }}$ siècle. À Nantes, les nom-

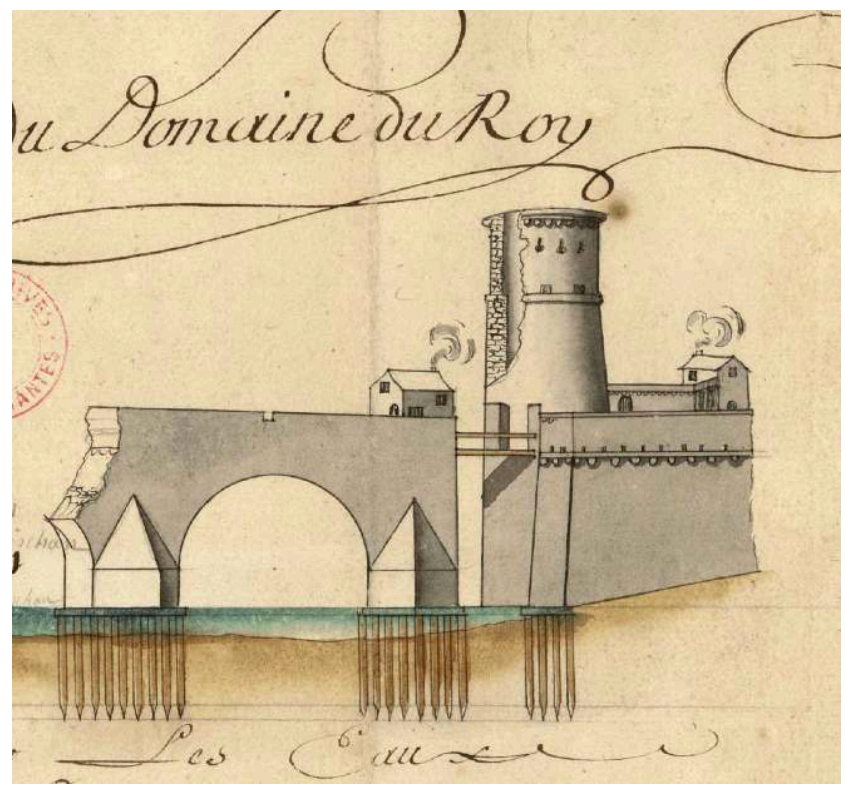

Figure 14 : La forteresse et une section du pont de Pirmil, sur la "Carte figurative contenant l'état ou se trouvent les pescheries de Pirmil, dépendantes du domaine du Roy» (vue de détail) par Bounin (1712) (Archives municipales de Nantes, II168/69). Figure 14: Pirmil fortress and a part of Pirmil bridge.

breux actes publiés de Jean $\mathrm{V}$ indiquent que pour résoudre ce problème, le duc engage une campagne de travaux de fortification. Toutefois, malgré ces premiers aménagements, les textes montrent que les travaux réalisés sont encore très insuffisants aux yeux du duc, et que les réparations et reconstructions doivent se poursuivre afin de doter la ville de défenses efficaces : "lesdites fortifficacions et emparement ont esté grandement augmentez, et y ont esté faiz pluseurs notables et prouffitables ediffices pour la seureté et deffense de nostredicte ville; et encores est de neccessité et besoing de y perserverer, pour ce que encores y a pluseurs murs en pluseurs endroiz qui riens ne valent, et les convient faire tout à neuff, avecques pluseurs autres reparacions qui y sont neccessaire" (Blanchard, 1889-1895, vol. 4, p. 226-227, acte $\mathrm{n}^{\circ} 2386$ ). Ces mêmes documents témoignent aussi de la volonté de la communauté urbaine d'adapter les fortifications aux progrès conjoints de l'artillerie mécanique et de l'artillerie à poudre. Dans les années 1424-1425, avec l'autorisation ducale, les représentants de la ville font ainsi aplanir la motte Châteaugaillard tout en faisant aménager plusieurs boulevards d'artillerie, au-devant de la porte Saint-Pierre et dans d'autres lieux non localisés précisément (Blanchard, 1889-1895, vol. 3, p. 125-126, acte $\mathrm{n}^{\circ} 1585^{20}$; La Nicollière-Teijeiro, $1883: 38-43$, acte

20. "Qu'il estoit expediant et neccessaire chose pour le bien et fortifficacion de nostredicte ville, faire avallet et unier une mote de terre qui est pres joignant la douve de nostredicte ville du cousté devers Richebourg, vulgaument appellée icelle mote Chasteaugaillart, tant pour ce que si elle demouroit en 
$\mathrm{n}^{\circ} \mathrm{XVI}^{21}$ ) (fig. 15). Les travaux de terrassement ont pour but d'empêcher d'éventuels ennemis de profiter de la situation de hauteur de la motte pour accroître la portée des tirs paraboliques de leurs pièces d'artillerie mécanique, tandis que l'aménagement de boulevards est destiné à permettre l'usage de pièces d'artillerie à poudre depuis l'enceinte urbaine, tout en renforçant cette dernière face aux tirs des batteries adverses. Si les premières mentions de l'utilisation de l'artillerie à poudre par la garnison ducale du château de la TourNeuve sont attestées dès la fin du XIv ${ }^{e}$ siècle (cf. supra), les premières modifications notables du système défensif urbain en lien avec cet usage ont donc lieu pendant le règne de Jean V. Ces travaux, qui consistent en la modification et en l'ajout d'ouvrages défensifs sur, ou en avant de ceux déjà existants, ouvrent donc la longue période d'adaptation des fortifications urbaines à l'artillerie à poudre, caractéristique $\mathrm{du} \mathrm{Xv}^{\mathrm{e}}$ siècle. La transformation du dispositif défensif de la ville initié par Jean $V$ nécessite toutefois de lourdes dépenses. Pour résoudre ce problème, le duc s'appuie sur les bourgeois nantais, auxquels il accorde de nouveaux privilèges, tandis que ceux-ci participent activement à la levée de nouvelles taxes dans la ville, puis à l'emploi de ces revenus pour les travaux de fortifications. Ces responsabilités sont respectivement déléguées à des "receveurs" et à des "miseurs". Parmi plusieurs impôts et taxes, ce sont les revenus issus de la taxe sur la vente du vin au détail dans les différents débits de boisson de la ville ("l'appeticement» ou «billot») qui semblent avoir fourni l'essentiel des fonds employés aux travaux de fortifications (Kerhervé, 1987, p. 652; Leguay et Martin, 1997, p. 251). L'étude des différents textes produits sous le règne de Jean $\mathrm{V}$ révèle que le budget réellement disponible pour les travaux de fortifications a souffert d'une perception d'impôt rendue difficile par de nombreuses franchises dont se prévalaient certains habitants, ainsi que de l'emploi des recettes à d'autres ouvres que la restauration de l'enceinte urbaine (Dreillard, 2015, p. 75-82). De plus, le pouvoir ducal et le conseil des bourgeois ont également

lestat ou elle est de present, elle seroit moult prejudiciable a nostredicte ville, pour ce que si ennemis y sourvenoint a puissance, [...] ilz la pourroint de legier fortiffier et emparer, et en icelle se loger pour grever et endomager nostredicte ville [...] que aussi mesmes en l'endroit ou elle est située convient de neccessité que le grant chemin et pavé soit fait pour yssir et aller de nostredicte ville et par le boulevert qui est fait de nouvel a la porte St Père, et descendre audit lieu de Richebourg." "

21. "La reparacion de notre ditte ville, quelle est la cleff de tout notre duchié, est tres necessaire a avancer parachever et accomplir, parce que elle touche et peut toucher la seurté garde et conservacion de nous, notre seignorie et de tout le pais, et que si il avenait, [...] que elle fust en main de nos ennemis, ce pourroit estre la perdicion et destrucion de nous et du parsurs de notre duchié; par quoy [...] es reparacions qui sont a faire neccessairement et hastivement, tant es murs de notre dite ville et des boulevars dicelle que es ponts et autres choses qui sont neccessaires pour le bien commun seurté et deffense de notre ditte ville." eu quelques difficultés à mettre en place un service de garde efficace dans la ville, tant au niveau des portes, que pour la mobilisation et la participation au guet. L'effort de mise en défense et de transformation des fortifications de la ville engagé sous Jean $\mathrm{V}$, bien qu'effectif, reste donc contrasté. Enfin, il convient de préciser qu'aucun vestige archéologique pouvant être attribué aux réalisations défensives de Jean $\mathrm{V}$ n’a jusqu’à présent été mis au jour à Nantes.

\section{L'intensification des travaux de fortification à l'approche du conflit franco-breton (1442-1491)}

Les successeurs de Jean V abandonnent la politique de " neutralité opportuniste " et participent activement aux dernières opérations de reconquête du royaume aux côtés des Français. Les ducs François I I ${ }^{\text {er }}$ (1442-1450) et Pierre II (1450-1457) font en effet le choix politique et pragmatique de soutenir la France, dont la victoire semble se dessiner à partir des années 1435 (Leguay et Martin, 1997 p. 194). Ceux-ci cherchent alors à préserver l'autonomie du duché en scellant des alliances officielles avec le roi de France, dans l'idée de conférer au duché de Bretagne un statut d' "état " allié, faisant le choix d'un libre soutien au royaume, et non d'un statut de fief de la couronne, qui interviendrait dans le cadre d'une obligation vassalique. Charles VII n'est pas en position de se passer de l'aide des troupes bretonnes et laisse donc les ducs se prévaloir de leur indépendance, en échange de leur participation à la reconquête du bassin parisien, de la Normandie et de l'Aquitaine. Toutefois, les rapports entre le duché et le royaume se modifient et se détériorent dès les années 1460. En effet, la monarchie française, qui sort renforcée de la guerre de Cent Ans, entend bien désormais affirmer son autorité sur les grands fiefs de la couronne, qui ont profité des années d'incertitude pour gagner en autonomie (ibid., p. 209).

Les sources textuelles de la seconde moitié du Xve siècle, et plus particulièrement les registres de comptes de construction (comptes des " miseurs ») conservés aux Archives municipales de Nantes (série CC), témoignent des nombreuses campagnes de travaux effectuées sur les fortifications de la ville durant cette période (fig. 15). Ainsi, entre 1444 et 1450 , la porte Saint-Nicolas est reconstruite et renforcée d'un boulevard d'artillerie (Le Mené, 1961, p. 386), tandis qu'un autre "belouard " est aménagé en avant de la porte Sauvetout sous Pierre II (1450-1457) (AMN DD 3). Cette mention textuelle pourrait correspondre aux vestiges du boulevard (tour du Bourreau), des courtines et de la tour circulaire (tour du Haut-Pas, fig. 16) mis au jour lors de campagnes de fouilles préventives (Guérin, 1998; Lacoste, 2012). La construction de ces ouvrages avancés provoque très probablement le comblement d'un fossé défensif du 


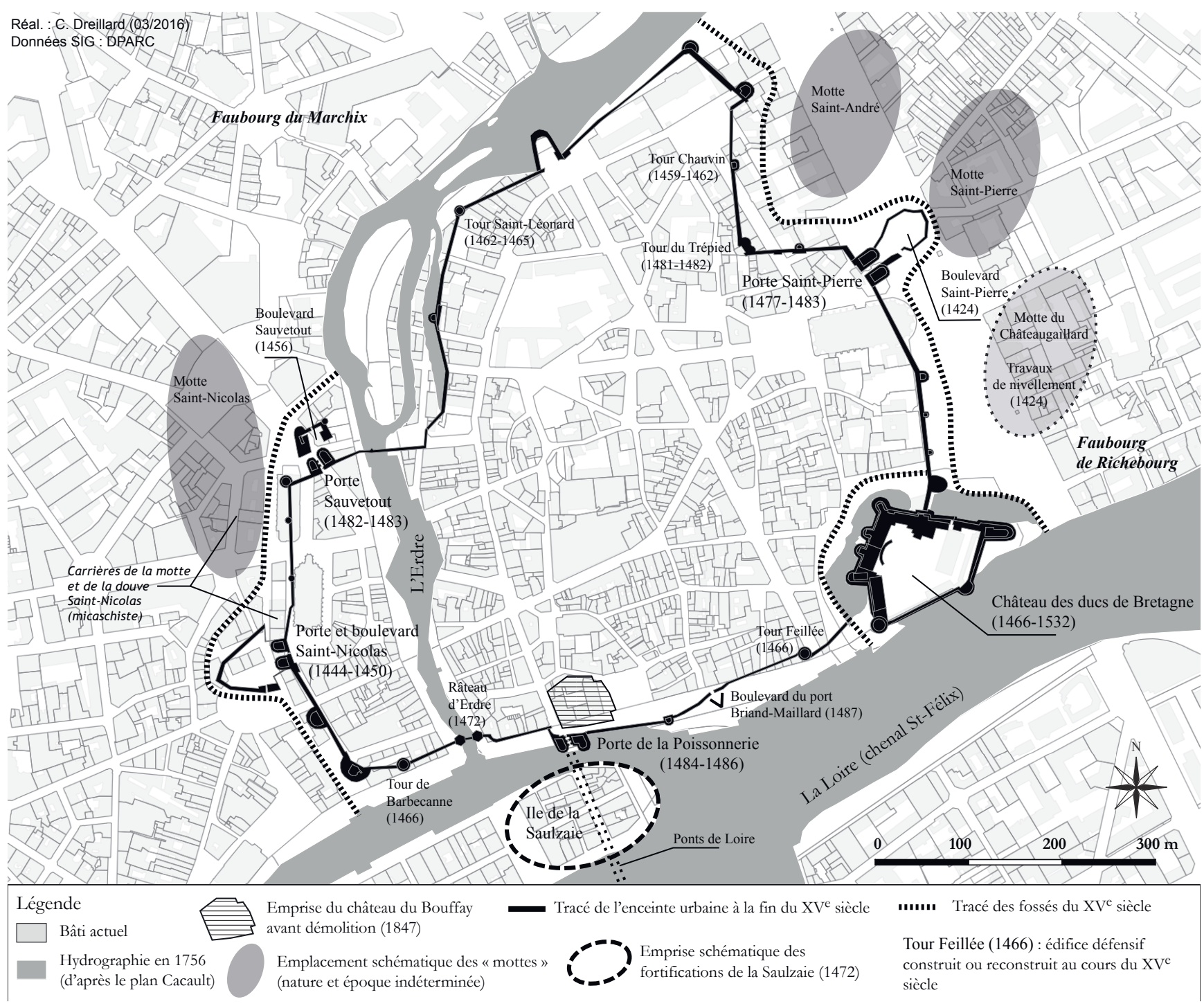

Figure 15 : Proposition de restitution des fortifications à la fin du Xve siècle (réal. : C. Dreillard; données SIG : DPARC). Figure 15: Urban fortifications at the end of the $15^{\text {th }}$ century.

XIII ${ }^{\mathrm{e}}$ siècle, dont le négatif a été identifié dans le substrat rocheux (Lacoste, 2012, p. 26). Ce comblement engendre vraisemblablement une nouvelle campagne de creusement de la douve protégeant ce front ouest, aujourd'hui matérialisée par la rue de l'Arche-Sèche, et qui constitue encore une rupture topographique dans l'espace urbain.

C'est toutefois pendant le règne de François II qu'ont lieu les plus importantes transformations du dispositif défensif urbain, dans un contexte de dégradation progressive des relations diplomatiques avec le royaume de France (Leguay et Martin, 1997, p. 390-406). De nouveau, ces travaux de fortification ont pour but d'adapter l'enceinte urbaine à l'usage de l'artillerie à poudre, tant au niveau de la défense passive que de la défense active. Ainsi, dès le début de son règne, François II signale que la construction de nouvelles murailles et de nouveaux boulevards, qui a été entamée par ses prédécesseurs, doit impérativement être poursuivie, tout comme l'achat de pièces d'artillerie ${ }^{22}$ : "en icelle notre ville, $y$ a beaulx et grans edifices des reparacions encommancez, qui sont nécessaires a parachever, en murailles, belouars, ponts, l'orloge et autres ouvraiges; et si ilz estoint laissez en lestat cherroint en decadence, au grant dommaige de nous, desdits habitans et de la chose publicque de notre pays [...]

22. La constitution d'un parc d'artillerie est une des préoccupations principales de la municipalité dans le dernier tiers du $\mathrm{Xv}^{\mathrm{e}}$ siècle puisque les comptes des miseurs font état de 121 canons en 1468, 159 en 1477, et 292 en 1487 (Leguay et Martin, 1997, p. 403). 


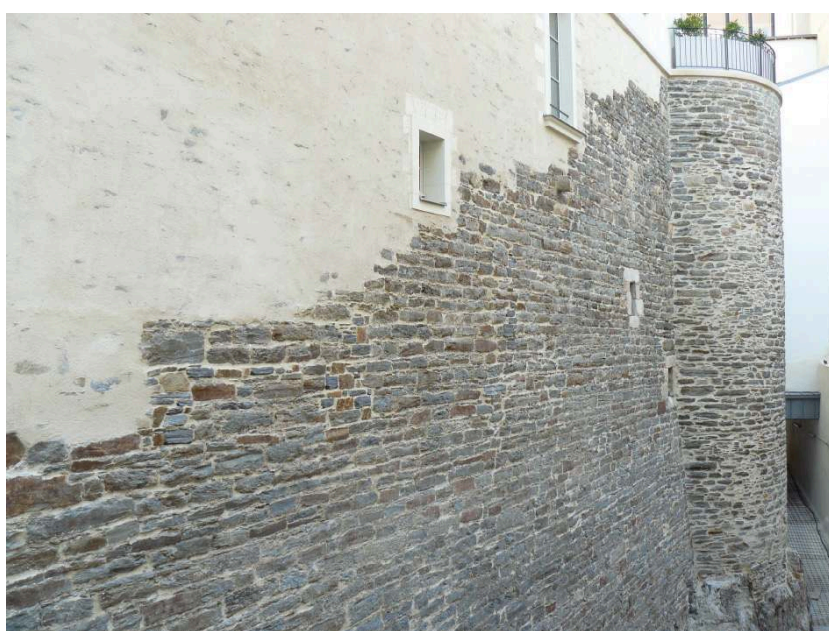

Figure 16 : Tour du Haut-Pas et courtine attenante (cliché C. Dreillard).

Figure 16: Haut-Pas tower and curtain wall.

Aussi $[. .$.$] y a neccessité dartillerie, et autres choses pour la def-$ fense conservation et bien de notre dicte ville " (La NicollièreTeijeiro, 1883 , p. 59-60, acte $\mathrm{n}^{\circ}$ XXII). Le duc donne alors aux représentants de la ville les moyens financiers nécessaires à la réalisation de ces travaux, en prolongeant et en leur octroyant de nouveaux droits et privilèges en matière de fiscalité et d'imposition ${ }^{23}$.

En 1466, le duc François II ordonne la reconstruction du château de la Tour-Neuve. Les termes de ce mandement, par ailleurs bien connus de l'historiographie nantaise ${ }^{24}$, sont assez explicites sur la nature des travaux engagés : l'édifice, trop petit et vétuste, doit être agrandi et remis à neuf pour remplir la double fonction de place forte et de palais ducal. Le château des ducs de Bretagne ${ }^{25}$ prend donc la forme d'un palais-forteresse doté de puissantes tours d'artillerie en schiste et en granit tout en disposant d'un luxueux corps de logis résidentiel en tuffeau, ouvert sur la cour intérieure (fig. 17). Outre la chronologie de construction de l'édifice,

23. Notamment les droits de pavage (taxe pour l'entretien des routes), de méage (taxe sur les marchandises transportées sur la Loire), du «denier pour livre " (taxe sur les marchandises vendues en gros), de l'appetissement (taxe sur les vins vendus au détail). La perception de ses taxes se heurte toutefois à de nombreuses fraudes, ce qui oblige le duc à mettre en place des organismes de contrôle (La Nicollière-Teijeiro, 1883, p. 64-66, acte $\mathrm{n}^{\circ}$ XXII).

24. « Nostre chastel de la Tour Neufve de Nantes [...] soit si petitement logé et indigent de reparacion que souventes foiz advient, quant aucuns princes ou seigneurs viennent devers nous, ne pouons ne nous est bonnement possible en iceli chastel les recevoir et loger ainsi honorablement et bien que faire le vouldrions, et lequel nostre chastel, pour lesdictes causes, avons volunté et grant desir de reparer et mectre en grant et bon appareill de logeis et fortifficacion, qui par ce mesmes pourra estre tourner au bien, sceurté et defense de nostredict pais" (La Borderie, 1991, p. 124-127, acte $n^{\circ}$ XXI).

25. Nom de l'édifice actuel.

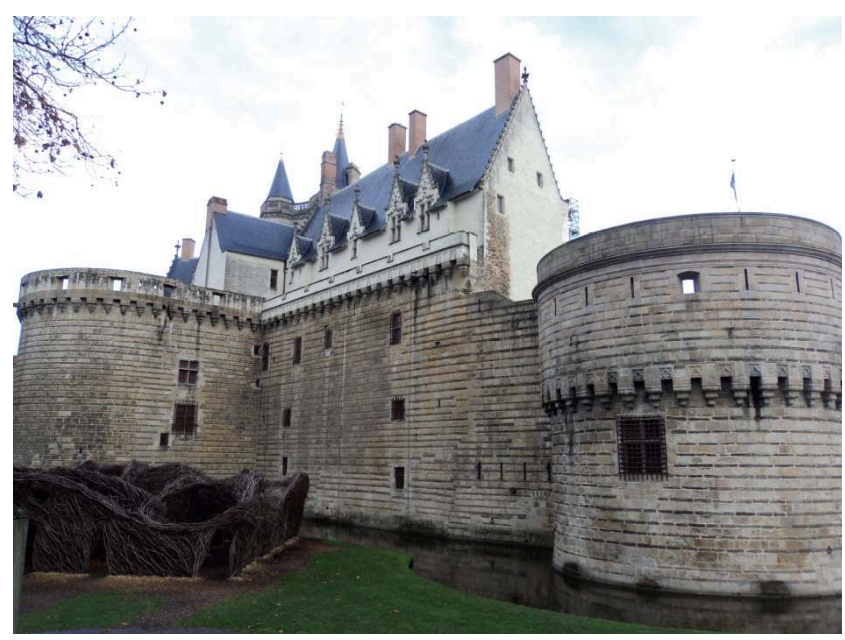

Figure 17 : Le château des ducs de Bretagne, du côté de la tour des Jacobins (à gauche) et de la tour du Port (à droite) (cliché C. Dreillard).

Figure 17: The castle of the Dukes of Brittany.

les opérations archéologiques effectuées dans le cadre de la rénovation du musée d'histoire de Nantes ont permis à J. Pascal (2014, p. 215-222) de mettre en évidence qu'un changement de projet avait eu lieu en cours d'aménagement. Un premier projet, identifiable aux nombreuses traces de repentirs de construction dans les niveaux inférieurs des édifices, prévoyait ainsi de suivre les différents niveaux de sols des cours du château primitif, avant d'être abandonné au profit de l'aménagement d'une cour de plain-pied.

Le dépouillement et l'étude détaillée du registre de compte du miseur de l'année 1466 (AMN CC 247, fo 1-fo 55) révèlent qu'en parallèle du chantier de reconstruction du château ducal, la majorité des éléments constitutifs de l'enceinte urbaine étaient concernés par des travaux de réfections ou d'entretien, tandis que deux tours du front sud étaient même en cours d'édification, la tour de Barbecanne ${ }^{26}$ et la tour Feillée $e^{27}$ (Dreillard, 2015, p. 107-134). L'année 1466 semble donc être une année charnière dans la transformation du dispositif défensif urbain. Cette étude textuelle apporte également quelques renseignements sur les techniques de construction et la nature des matériaux utilisés pour édifier les nouvelles fortifications. En 1466, deux types de pierres sont ainsi principalement employés : le granit et le mica-

26. D'avril à décembre, le registre relate les dépenses liées à la mise en place des fondations de la tour et des premières assises de granit et de micaschiste constituant l'élévation de l'édifice, non achevé à l'arrivée de l'hiver, mais qui compte déjà plusieurs canonnières.

27. De février à juin, le registre signale, entre autres, l'aménagement de maçonneries, de canonnières, de merlons, et de mâchicoulis de granit liés au mortier de chaux, ainsi que la pose d'au moins deux niveaux de plancher. 
schiste. Ces roches sont respectivement extraites des carrières périurbaines situées sur les rives de la Sèvre Nantaise et dans le secteur d'Orvault, et des carrières urbaines de la " motte » et de la douve Saint-Nicolas sur le front ouest (fig. 15). Il convient de noter que l'utilisation de ces deux matériaux est également attestée par l'archéologie sur plusieurs vestiges de l'enceinte urbaine de la seconde moitié du $\mathrm{Xv}^{\mathrm{e}}$ siècle (porte Sauvetout, tour Saint-Jacques, tour de l'Évêché) ainsi que sur le château ducal. Il est donc possible de supposer qu'un programme architectural commun, basé sur l'alternance d'assises de granit et de micaschiste/schiste, ait pu être mis en œuvre conjointement par le duc et les institutions municipales. L'étude du registre de 1466 a aussi révélé l'existence de fondations sur pieux (en bois d'aulne) pour les murs élevés dans le substrat mouvant du bord de la Loire. L'aménagement de ces fondations a d'ailleurs nécessité la mise en place de digues temporaires, fabriquées à l'aide de planches en bois étanchéifiées à l'aide de peaux, ainsi qu’une évacuation constante de l'eau par des ouvriers.

En 1471, la "modernisation » de l'enceinte urbaine parait avoir déjà bien progressé, mais n'est toujours pas achevée, si l'on se réfère à un acte ducal qui mentionne de "beaulx et sumptueux ouvraiges " déjà réalisés, "tant en portaux, tours, saincture de muraille, belouars, ponts, artillerie que autre chose ", mais qui nécessitent "encore de grande mise a parachever et entretenir" (La Nicollière-Teijeiro, 1883, p. 70-71, acte $n^{\circ}$ XXVII). Entre 1472 et 1478, c'est l'île de la Saulzaie qui semble être dotée d'une enceinte maçonnée et de tours (AMN CC 249; Travers, 1836, vol. 2, p. 161; Martineau, 2001, p. 8), dont des vestiges, rejetés en position secondaire dans le lit de la Loire, ont vraisemblablement été mis au jour lors la fouille préventive du "Carré Feydeau " (Mercier et al., 2014). Une dernière grande phase de fortification paraît s'ouvrir en 1477, après la mort de Charles le Téméraire (duc de Bourgogne et allié ligueur de François II), qui place la Bretagne en position de dernier grand fief autonome du royaume de France. Les comptes des miseurs signalent en effet que l'énergie des édiles nantais se concentre alors sur la reconstruction en dix ans de trois des quatre grandes portes de l'enceinte urbaine : la porte Saint-Pierre de 1477 à 1483 (Armide, 2005, p. 46-49), la porte Sauvetout de 1482 à 1483 (Martineau, 2001, p. 8-11) (fig. 18) et la porte de la Poissonnerie de 1484 à 1486 (Le Méné, 1961, p. 387 388) (fig. 15). Les opérations archéologiques ${ }^{28}$ menées sur ces trois portes y ont révélé l'application de principes architecturaux similaires, à savoir le flanquement du passage traversant par deux tours d'artillerie en forme de fer à cheval disposant de plusieurs niveaux de casemates. Ces ouvrages

28. Guérin, 1995; 1998; Martineau, 2001; Augry et al., 2014; Laurens-Berge, 2014a; Pacaud, 2014; Lacoste, 2014.

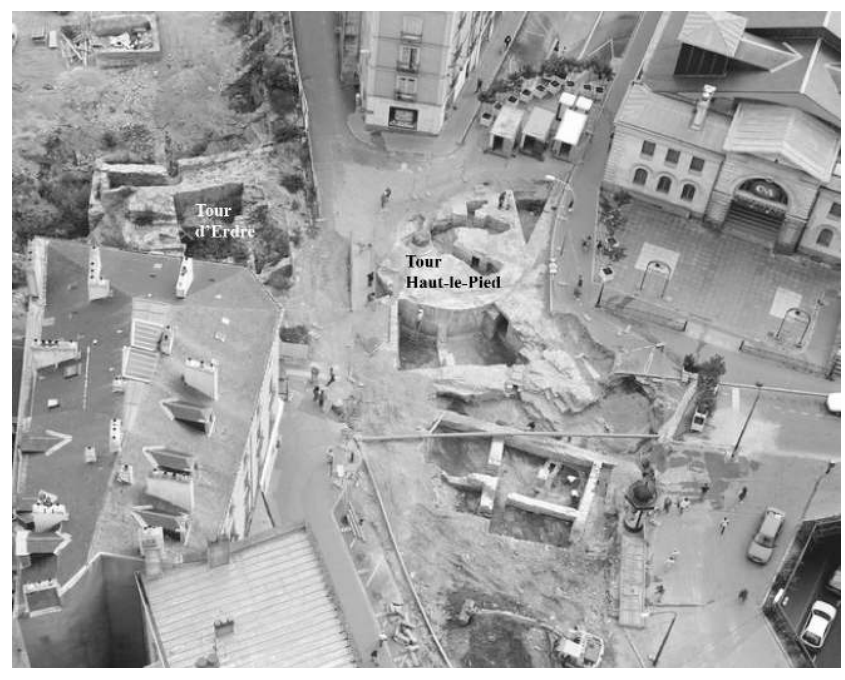

Figure 18 : Vue de la porte Sauvetout en cours de fouille (1998) (cliché D. Pillet (C) Région Pays de la Loire - Inventaire général). Figure 18: Sauvetout gate during the excavations in 1998.

sont représentatifs du " modèle breton " développé sous François II et qui confère à la tour d'artillerie un véritable rôle offensif de contre-batterie (Martineau, 2011, p. 211). Les sources textuelles témoignent également de ces efforts effectués au niveau de la défense active. Sur la volonté des ducs et des bourgeois, la ville s'équipe ainsi d'un important parc d'artillerie (Armide, 2011). Dans le même ordre d'idée, les ducs encouragent les habitants à utiliser les armes de trait par l'intermédiaire du jeu du Papegault ${ }^{29}$ et la création d'une milice paroissiale de francs-archers, dans l'optique de former la population à se défendre efficacement en cas de conflit armé avec le royaume de France (Leguay et Martin, 1997, p. 403).

Cette crainte du conflit armé est justifiée, puisque celui-ci finit effectivement par débuter au mois de mai 1487. Les troupes royales pénètrent dans le duché et prennent sans trop de difficultés plusieurs grandes villes et places fortes bretonnes, qui ouvrent généralement leurs portes après quelques jours de canonnade. Le siège de Nantes débute quant à lui le 19 juin 1487. En prévision de ce siège, le duc et les bourgeois ont fait exécuter des travaux de mise en défense de dernière minute ${ }^{30}$. L'armée française positionne certaines de ses pièces d'artillerie au niveau des mottes Saint-Pierre et

29. Le jeu du Papegault, pratiqué dans les principales villes de Bretagne, est un concours de tir réservant aux gagnants certains avantages fiscaux, officialisés par mandement ducal en 1482 (La Nicollière-Teijeiro, 1883, p. 72-73, acte $\mathrm{n}^{\circ}$ XXVIII). À Nantes, la tour du Papegault, située sur le front est, témoigne aussi de la pratique de ce jeu.

30. Expropriations et démolition de maisons aux abords de l'enceinte, curage des douves, renforcement des points stratégiques de l'enceinte (poternes, portes...) (Warner 1994-1995, p. 60-61; Leguay, 2007, p. 126). 
Saint-André ${ }^{31}$, confirmant par ailleurs les inquiétudes de la ville quant au danger que constituent ces élévations pour la défense de cité. Les Nantais parviennent néanmoins à garder le contrôle de leurs accès au fleuve, ce qui leur permet de recevoir du ravitaillement depuis d'autres villes bretonnes (Moal, 2009, p. 82). Les fortifications résistent aux assauts des troupes françaises qui finissent par lever le siège le 6 août 1487. La politique de fortification et de reconstruction de l'enceinte urbaine entamée par Jean $V$ et poursuivie jusqu'à François II semble donc avoir été efficace, puisque la cité des ducs est en capacité de tenir tête aux batteries d'artilleries françaises pendant près de deux mois, alors que les autres villes du duché tombent ou capitulent au bout de quelques jours (Warner, 1994-1995). Néanmoins, les dégâts ont sans doute été importants, car dès la fin du siège, François II ordonne à ses officiers de "réparer les murailles de la dite ville du dommage qu'elles ont souffert pendant viii semaines de siège" (Lobineau, 1707, t. 2, p. 1458). Il est par ailleurs important de souligner que lorsque la cité passe finalement sous la bannière royale en 1490, cela se fait à la suite d'une trahison $^{32}$, qui entraîne la perte de contrôle par les Nantais du château ducal, élément clé du dispositif défensif urbain, et non après une défaillance des fortifications apparue au cours d'un assaut ou d'un siège.

\section{LES FORTIFICATIONS DE LA FIN DE L'INDÉPEN- DANCE DE LA BRETAGNE À LA SIGNATURE DE L'ÉDIT DE NANTES (XVI ${ }^{\mathrm{E}}$ SIÈCLE)}

\section{Des fortifications entretenues pour la défense du royaume? (1491-1559)}

Le mariage de la duchesse Anne et du roi Charles VIII en 1491, qui conclut le conflit franco-breton, marque également la fin de la période "d'indépendance " du duché de Bretagne, avant le rattachement officiel du duché à la couronne de France en 1532. Aucun indice textuel ou archéologique ne témoigne d'une éventuelle volonté royale de démantèlement des fortifications urbaines après le conflit, malgré les difficultés qu'elles avaient posées aux troupes françaises lors du siège de 1487. La ville bénéficie peut-être de sa fonction de port et de point de contrôle de l'estuaire de la

31. Ainsi, dans une lettre de 1487 du chancelier de Bretagne aux habitants de Guingamp publiée par D. Morice (1742-1746, p. 547, t. 3), on apprends que "les Français arriverent es faubourgs de Saint-Clément et de Richebourg à Nantes ou ils sont, et le second coup d'artillerie qu'ils tirèrent fust d'une serpentine a la fenestre de la chambre ou le Duc avoit accoutume de coucher".

32. Alain D'Albret, chef de la garnison du château, livre le château (qui dispose de ses propres accès vers l'extérieur de la ville) aux Français dans la nuit du 19 au 20 mars 1490.
Loire pour maintenir ses défenses fonctionnelles, alors même que le royaume fait face à différentes coalitions européennes dans le cadre des guerres d'Italie (1494-1559). Quelques renseignements sur l'état des fortifications nantaises au début du XvI ${ }^{\mathrm{e}}$ siècle peuvent être tirés des textes produits par la chancellerie d'Anne de Bretagne, qui continue d'administrer le duché jusqu'à sa mort en 1514 (Leguay et Martin, 1997, p. 425). Ces documents indiquent ainsi que la ville est "fort emparée de murailles, tours, boulouars, fossés et artillerie, et autres sumptueux ouvraiges et eddifices ", qui nécessitent cependant un entretien constant et des réparations, pour lesquels la reine et duchesse prolonge régulièrement les privilèges de la communauté urbaine en matière de fortifications (La Nicollière-Teijeiro, 1883 , p. 82-86, actes $n^{\circ}$ XXXI et

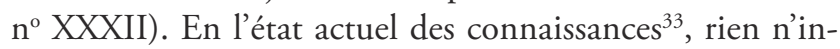
dique cependant que l'enceinte urbaine ait connue d'importants remaniements dans la première moitié du XVI ${ }^{e}$ siècle. En effet, les seuls travaux de fortification attestés à Nantes pour cette période concernent le château des ducs (devenu résidence royale), dont les tours et les courtines proches de la Loire sont achevées vers 1532 (Pascal, 2014, p. 219-222; Jouzeau, 2013, p. 216). Il est tout de même possible que les institutions municipales et les ingénieurs royaux aient continué (ou tout du moins souhaité) « tenir à jour » le dispositif défensif nantais, en s'inspirant par exemple des nouvelles techniques de défense et de flanquement des places fortes développées pendant les guerres d'Italie, qui conduisent à l'apparition de la fortification bastionnée (Faucherre, 1996, p. 19-28).

\section{Les travaux de fortifications pendant les guerres de Religion : remaniement de l'enceinte médiévale et protection du faubourg du Marchix (1562-1598)}

Plusieurs aménagements défensifs majeurs sont effectués à Nantes dans le contexte des guerres de Religion. Deux phases peuvent être distinguées dans les motivations liées à ces réalisations. Dans un premier temps (1562-1584), c'est la crainte des offensives des protestants qui pousse la ville à se fortifier puis à faire ériger (sur ordre royal) une nouvelle enceinte bastionnée autour du faubourg du Marchix. Dans un second temps (1584-1598), c'est le duc de Mercœur (gouverneur de Bretagne et membre de la Ligue catholique) qui fait poursuivre la campagne de fortification pendant sa rébellion contre les rois Henri III et Henri IV. Bien que seul le bastion de Rennes soit encore aujourd'hui partiellement conservé en élévation (fig. 19) et qu’aucun autre vestige n’ait

33. Le dépouillement exhaustif des comptes des miseurs conservés pour le $\mathrm{XVI}^{\mathrm{e}}$ siècle pourrait par exemple rendre compte d'aménagements dépassant les simples travaux d'entretien. 


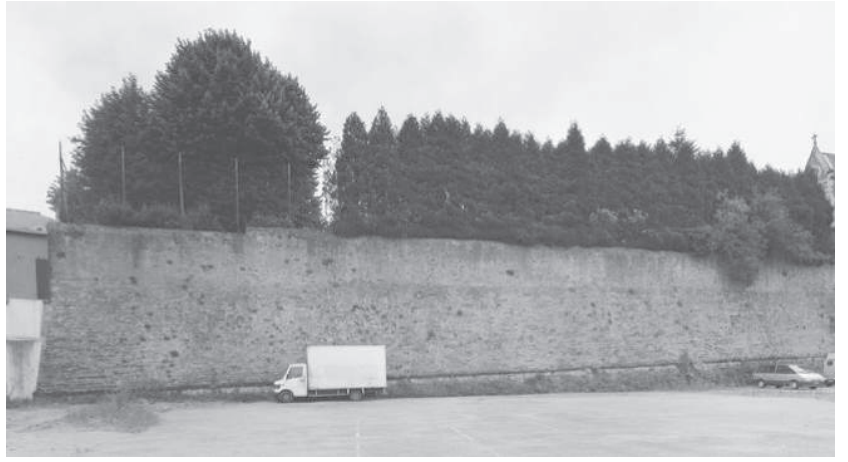

Figure 19 : Le bastion de Rennes en 1998 (D. Pillet (C) Région Pays de la Loire - Inventaire général).

Figure 19: Rennes bastion in 1998. été mis au jour lors d'une campagne archéologique, l'enceinte du Marchix est néanmoins relativement bien connue par l'intermédiaire des sources textuelles et planimétriques. Ces documents ont permis à I. Rouaud-Rouazé (1997) et G. Saupin (1998) de présenter les principales caractéristiques de construction de l'ouvrage. Si il ressort de ces études que la nouvelle enceinte n'a vraisemblablement jamais été terminée et n'a été maçonnée qu'en certains endroits, l'emprise générale des remparts et fossés peut être assez précisément restituée à partir de l'analyse des plans anciens et du parcellaire actuel (fig. 20).

En parallèle de la fortification du quartier du Marchix situé en surplomb de la ville, d'autres aménagements de

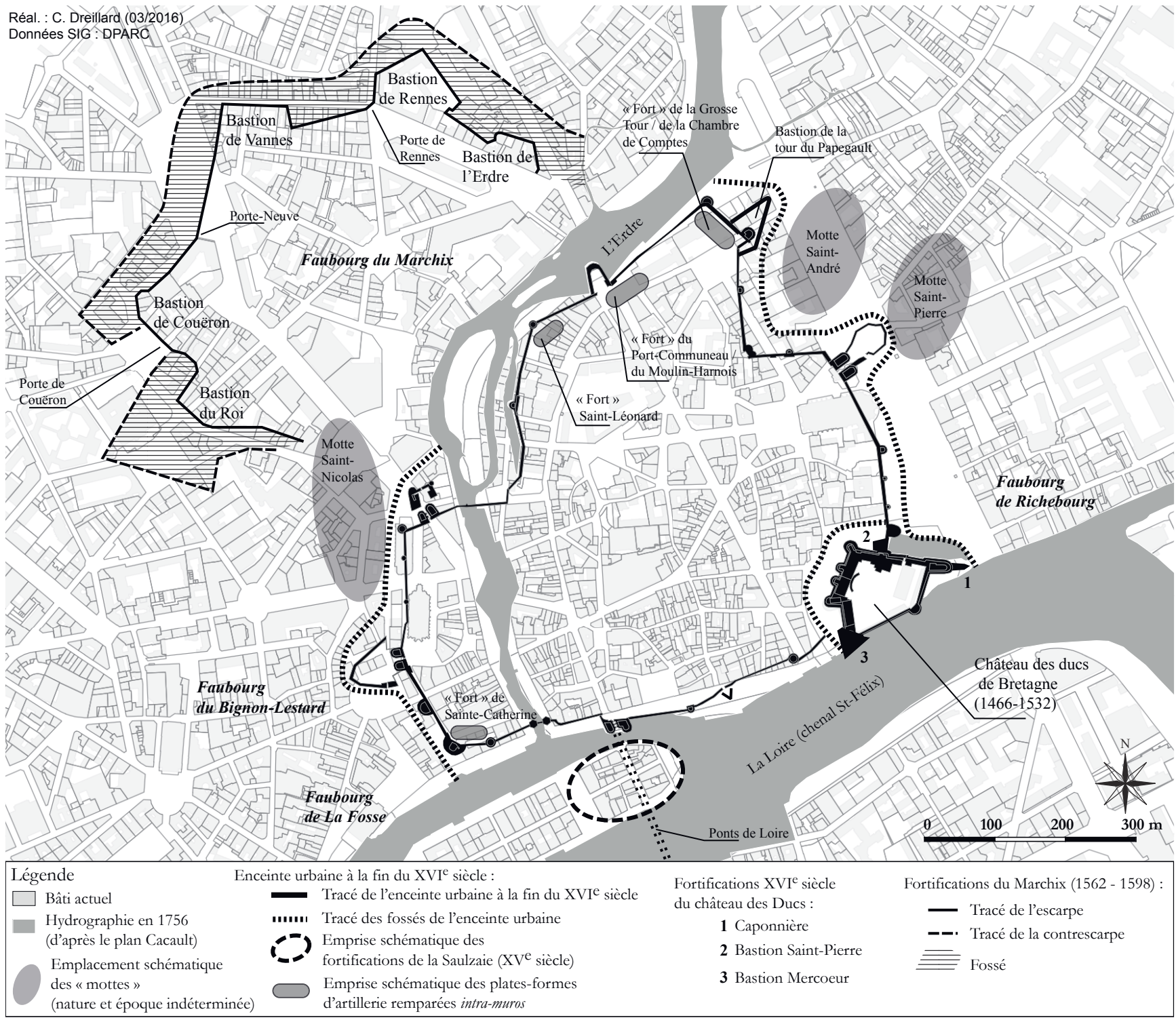

Figure 20 : Proposition de restitution des fortifications à la fin du XVI ${ }^{\mathrm{e}}$ siècle (réal. : C. Dreillard; données SIG : DPARC). Figure 20: Urban fortifications at the end of the $16^{\text {th }}$ century. 
plus petite envergure sont effectués au niveau de l'enceinte médiévale afin d'augmenter sa capacité défensive. Parmi les nombreuses réalisations attestées par les sources textuelles, planimétriques, archéologiques ou encore iconographiques, il convient tout d'abord de mentionner l'édification de plates-formes d'artillerie remparées intra-muros, utilisant vraisemblablement les courtines médiévales comme murs de soutènement. Trois de ces "forts de terre " sont situés le long du front nord de l'enceinte, près de la tour du PortCommuneau, de la tour Grosse-Tour et de la tour SaintLéonard (Travers, 1836, vol. 2, p. 402, 410; Croix, 2006, p. 548). Un autre « fort » est quant à lui localisé au niveau de la place Sainte-Catherine, tandis qu'un dernier (non localisé précisément, mais complété de fossés) est aménagé par les habitants des faubourgs de la Fosse et du Bignon-Lestard (Saupin, 1998, p. 150). Les fortifications médiévales sont également renforcées par des ouvrages maçonnés et casematés de type bastion et caponnière (fig. 21 et 22), et certaines courtines sont rehaussées au niveau des tours afin de faciliter la circulation des pièces d'artillerie (désormais mobiles) sur l'intégralité du périmètre fortifié. Dans ce contexte de guerre civile et de suspicion religieuse, une attention particulière est également portée au contrôle des accès à la ville, qui sont limités (portes et poternes murées partiellement) et renforcés (réfection des ponts-levis et battants de portes). Une ordonnance du lieutenant-général de Bretagne de l'année 1568, transcrite par N. Travers (1836, vol. 2, p. 412), témoigne bien par ailleurs de l'agitation et des nombreux travaux de mise en défense effectués dans la crainte d'une attaque sur la

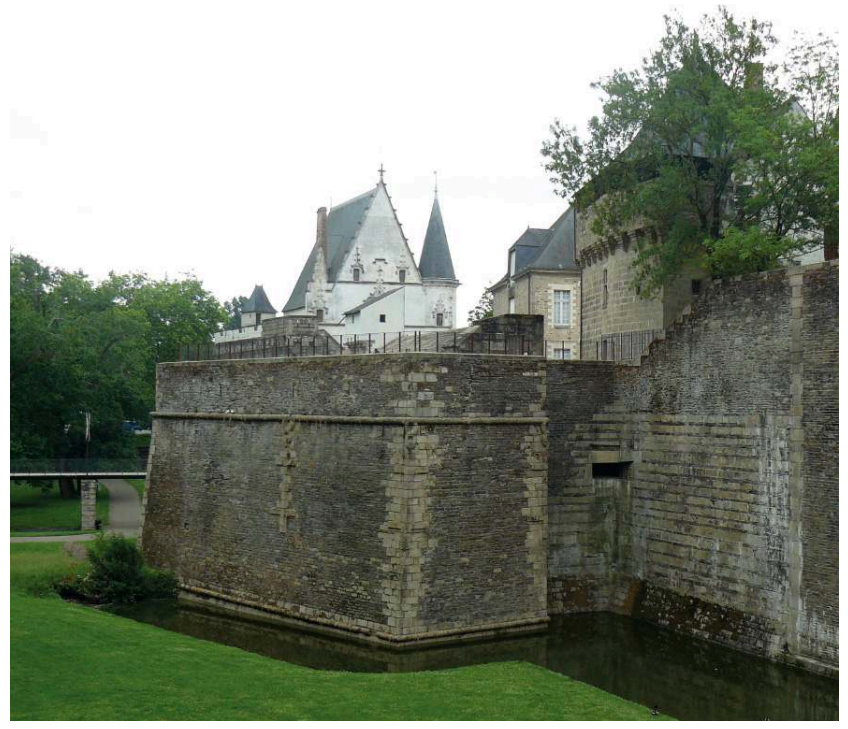

Figure 21 : Le bastion Saint-Pierre (château des ducs de Bretagne) (cliché C. Dreillard).

Figure 21: Saint-Pierre bastion. ville : «Premièrement faire le fort de Sauvetour. Reste y mettre cinquante bottiers, douze macsons, huit manouvres. [...] Pour régaler [niveler] la motte Saint-André, devant le Trépier, trente pionnier, attendant achever ce qui reste audit Trépier. Pour la tour du Duc, quatre macsons, quatre manouvres et deux charpentiers. Pour le derrière des Jacobins, trois macsons et quatre manouvre. [...] Il est ordonné que Me Pierre Hudes dit Desclat [...] architecte, entrepreneur des fortifications de ceste ditte ville, fera besoingner en toute diligence aux lieux et endroits cy-dessus, [...] et aux maires et eschevins de laditte ville faire faire lesdites mises nécessaires auxdites fortifications. "Le duc de Mercœur se soumet finalement à Henri IV contre une compensation financière en 1598. Le chef ligueur remet alors la ville de Nantes au roi, qui vient y signer l'édit de tolérance du protestantisme, marquant la fin des guerres de Religion.

\section{LES FORTIFICATIONS FACE AUX TRAVAUX DE DÉMANTÈLEMENT (XVII ${ }^{\mathrm{E}}$ SIÈCLE-XIX ${ }^{\mathrm{E}}$ SIÈCLE)}

\section{Un dispositif défensif encombrant mais conservé en élévation ( $\mathrm{XVII}{ }^{\mathrm{e}}$ siècle)}

D'après les sources textuelles étudiées par I. RouaudRouazé (1997, p. 19, 25), il semble que les travaux de fortification du Marchix n'aient jamais repris après 1598, bien que le pouvoir royal ait cherché à les relancer et à maintenir la ville et le faubourg en état de défense, dont les bastions maçonnés, les tertres et les fossés sont convoités par les habitants de la ville pour leurs matières premières et leurs espaces constructibles. La problématique est similaire au niveau de

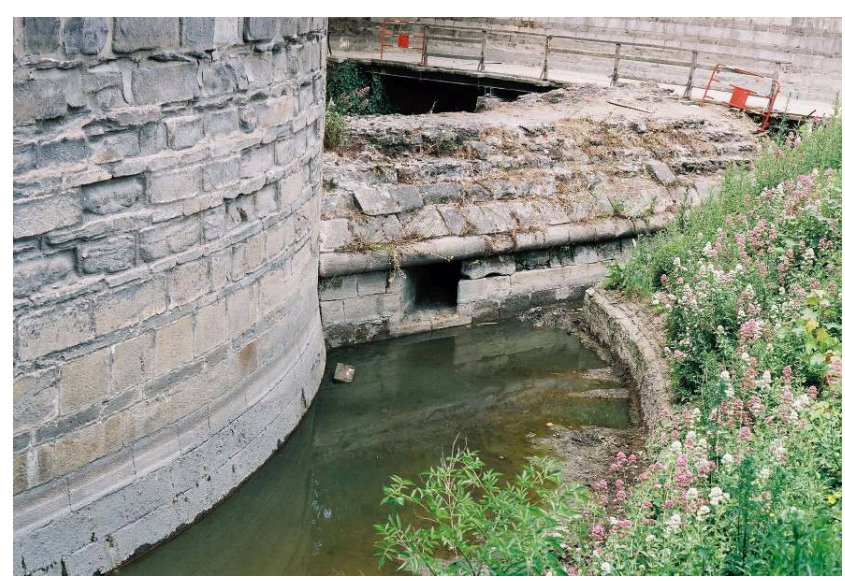

Figure 22 : Vestiges de la caponnière au pied de la tour du Fer-àCheval (château des ducs de Bretagne) (cliché J. Pascal, INRAP). Figure 22: Remains of the "caponnière" at the base of the Fer-à-Cheval tower. 
l'enceinte médiévale, qui commence à constituer un obstacle à l'urbanisation, malgré l'importance (au moins symbolique) que lui accordent encore la communauté urbaine et les représentants du roi. La construction d'une nouvelle section de courtine en 1658 entre la porte Saint-Pierre et la tour du Mûrier afin de permettre l'agrandissement du chevet de la cathédrale illustre bien cette évolution. En effet, si un nouveau mur est bien élevé pour ne pas rompre le périmètre fortifié (fig. 4), d'après les observations archéologiques effectuées par N. Lacoste (2014, p. 56-59) et l'étude des sources textuelles effectuée par G. Durville (1910, p. 1-25), il semble, qu'à l'exception d'une "guérite en saillie " "à la pointe $[. .$.$] de ladite muraille ", aucun aménagement lié à$ l'usage des armes à feu et batteries d'artillerie ne semble avoir été prévu pour renforcer cette courtine. Un soin particulier est cependant porté au parement extérieur de la muraille, qui doit être "belle et $[\ldots]$ unie ", d'après le devis de construction (Durville, 1910, p. 18). La courtine sert donc autant d'élément de défense passive que de marqueur topographique et symbolique des limites de la ville. Les riches descriptions de F.-N. Dubuisson-Aubenay (Croix, 2006, p. 511-773), de passage à Nantes en 1636, témoignent par ailleurs de l'importante place prise par les fortifications dans le paysage monumental de la ville au XviI ${ }^{\mathrm{e}}$ siècle, bien que celles-ci soient alors visiblement peu entretenues et parfois laissées à l'état d'abandon.

\section{Les grands travaux de démantèlement et les plans « d'embellissement " de la ville (XVIII ${ }^{\mathrm{e}}$-XIX ${ }^{\mathrm{e}}$ siècles)}

Le déclassement définitif et le démantèlement des fortifications urbaines s'opèrent progressivement tout au long du XVIII ${ }^{e}$ siècle et dans la première moitié du XIX ${ }^{e}$ siècle. En effet, au cours de cette période, la ville fait réaliser par ses architectes-voyers plusieurs campagnes d'alignements de façades et de rues et de créations de places et de quais, qui sont coordonnées au sein de grands plans d'embellissements urbains ${ }^{34}$. Ces réaménagements doivent permettre de désenclaver la vieille ville par la création de nouveaux axes de circulation et la restructuration de certains îlots d'habitations fortement contraints par les vieux murs d'enceinte. Certaines sections des fortifications sont donc démolies, d'autres sont réemployées et intégrées à des édifices civils et religieux ; les boulevards de circulation succèdent aux boulevards d'artillerie, les fossés défensifs sont comblés et les " mottes » sont nivelées afin de la laisser la place à de vastes espaces de promenades... Les fortifications médiévales et

34. L'œuvre des architectes-voyers nantais a récemment été étudiée en détail par G. Bienvenu (2013) dans le cadre d'une thèse d'histoire de l'architecture. modernes disparaissent donc en grande partie pendant les travaux d'urbanisme des XVIII ${ }^{\mathrm{e}}$ et $\mathrm{XIX}^{\mathrm{e}}$ siècles, avant d'être peu à peu "redécouvertes " à l'occasion des investigations archéologiques menées lors des aménagements urbains du $\mathrm{Xx}^{\mathrm{e}}$ siècle et du début du $\mathrm{XXI}^{\mathrm{e}}$ siècle.

\section{ConClusion}

Cet état des connaissances historique et archéologique permet de faire le point sur l'évolution chronologique, topographique et typologique des fortifications de la ville de Nantes. Outre l'adaptation constante du dispositif défensif au gré de l'évolution de l'armement et de la poliorcétique, cette étude diachronique montre également l'importance du contexte politique et militaire dans la mise en ouvre, ou l'absence, de travaux de fortifications. Cette conclusion rejoint le constat dressé par L. Bourgeois (2013, p. 473-474) qui, rappelant les études de P. Contamine (1978, p. 28-46) et de M. Fixot (1980, p. 509-522), souligne que d'une manière générale les fortifications urbaines médiévales ne sont réparées ou construites qu'à l'approche d'un danger, et sont laissées à l'abandon, ou sont employées à d'autres usages, le reste du temps.

En effet, en résumant très sommairement les grandes phases de travaux de fortifications de la ville, les aménagements des réduits défensifs, tertres, fossés et murs sont tout d'abord motivés par la menace viking et la vétusté de l'enceinte antique ( $\mathrm{x}^{\mathrm{e}}$ siècle). Ils sont ensuite effectués dans le cadre du conflit entre les comtes et évêques nantais et rennais ( $\mathrm{XI}^{\mathrm{e}}$ siècle), avant d'être stimulés par les différentes luttes politiques entre les Plantagenêts et les Capétiens (fin $\mathrm{du} \mathrm{XII}{ }^{\mathrm{e}}$ siècle). Dans la première moitié du XIII ${ }^{\mathrm{e}}$ siècle, la grande enceinte de réunion et le château de la Tour-Neuve peuvent être considérés comme les symboles monumentaux de la politique de renforcement du pouvoir ducal menée par Pierre de Dreux et Jean le Roux contre le roi de France, l'épiscopat et la noblesse bretonne, mais sans oublier qu'ils sont avant tout des ouvrages défensifs destinés à protéger la ville des conflits militaires engendrés par cette politique. L'absence d'indices textuels et archéologiques indiquant d'éventuels travaux de fortifications effectués à Nantes de la seconde moitié du XIII ${ }^{\mathrm{e}}$ siècle jusqu'au début de la guerre de Succession de Bretagne (1341) est peut-être due à la relative " tranquillité » militaire et à la stabilité politique du duché au cours de cette période. Le conflit de succession (13411364) semble principalement donner lieu à des travaux de mise en défense des fortifications déjà existantes gérés par la communauté urbaine, avant que Jean IV, vainqueur du conflit et soucieux d'établir son autorité sur une ville qui lui était opposée, ne fasse réaliser quelques réparations et 
réaménagements à la fin du XIV siècle (construction de la forteresse de Pirmil, possible extension du château de la Tour-Neuve). Au Xve siècle, la reconstruction de l'enceinte urbaine et du château ducal, initiée sous Jean V et achevée sous François II, s'accélère au fur et à mesure que se dégradent les relations avec le royaume de France et que s'avance la menace du conflit armé. Cette " modernisation " des fortifications, conjointement portée par le pouvoir ducal et la communauté urbaine, est efficace, puisque la ville résiste aux batteries d'artillerie françaises en 1487. Le rattachement du duché au royaume met fin au rôle politique central de Nantes et aucune campagne de fortification, ou de démantèlement, ne semble attestée dans la première moitié du XvI ${ }^{\mathrm{e}}$ siècle. Ce n'est qu'avec les troubles des guerres de Religion (1562-1598) que d'importants travaux de fortifications et de mise en défense sont de nouveau réalisés (enceinte bastionnée du Marchix, plates-formes d'artillerie intra-muros), d'abord dans la crainte d'un assaut des protestants, puis dans l'optique d'une opposition aux troupes royales. En l'absence d'autres menaces militaires majeures ou crises politiques, les fortifications sont ensuite peu à peu abandonnées, avant d'être démantelées au cours des XVIII ${ }^{\mathrm{e}}$ et XIX ${ }^{e}$ siècles dans le cadre des grands travaux d'urbanisme.

Enfin, il convient d'insister sur la méconnaissance actuelle de plusieurs éléments des fortifications, qui ne sont parfois simplement qu' " entr'aperçus " par l'intermédiaire des sources textuelles ou planimétriques, qui ne permettent pas d'en appréhender la nature, la datation et la pérennité avec certitude. De nouvelles observations archéologiques paraissent en effet nécessaires pour nuancer, critiquer et compléter les interprétations présentées dans le cadre de cette synthèse, dont la motivation initiale était justement de faciliter de futures recherches ${ }^{35}$.

\section{Remerciements}

La présente étude ainsi que les deux mémoires de recherche dont elle est principalement tirée n'auraient pas pu être réalisés sans les nombreux conseils et/ou diverses relectures d'Y. Henigfeld (université de Nantes), de M. LaurensBerge, N. Lacoste, C. Le Boulaire et F. Mercier (DPARC), de J. Martineau (SRA Pays de la Loire), ainsi que de S. Augry et J. Pascal (INRAP). Qu'ils en soient tous ici grandement remerciés.

35. Depuis la rédaction de cet article, il convient de mentionner qu'une partie de la tour du Connétable et d'une courtine attenante ont été mises au jour lors d'un diagnostic archéologique. Cette tour, située à l'angle sud-ouest de l'enceinte urbaine et protégeant le port médiéval, dispose du parement alterné schiste/granit caractéristique de la grande campagne de fortification de la seconde moitié du Xv siècle (Laurens-Berge M., Dreillard C., Square Fleuriot de Langle, DPARC, octobre 2017).

\section{Bibliographie}

Armide A., 2005 - La Porte Saint Pierre à Nantes : étude architecturale d'un édifice militaire fortifié urbain du $15^{e}$ siècle en Bretagne, Mémoire de maîtrise, Université de Paris 4 Sorbonne, 81 p.

Armide A., 2011 - "Les comptes et inventaires d'artillerie de la ville de Nantes (1457-1496) ", in Prouteau N. et al. (dir.), Artillerie et fortifications, 1200-1600, Rennes, Presses universitaires de Rennes, p. 165-178.

Augry S. et al., 2014 - Nantes, Neptune - Bouffay, rapport de fouille archéologique, INRAP Grand Ouest, 4 vol.

BAudry M.-P., 2011 - "La porte Mordelaise de la ville de Rennes ", in Prouteau N. et al. (dir.), Artillerie et fortifications, 1200-1600, Rennes, Presses universitaires de Rennes, p. $179-190$.

BiEnvenu G., 2013 - De l'architecte voyer à l'ingénieur en chef des services techniques. Les services d'architecture et d'urbanisme de la ville de Nantes du xviiie siècle au $x x^{e}$ siècle, Thèse de doctorat, Université de Paris 1, 3 vol.

Blanchard R., 1889-1895 - Lettres et mandements de Jean V, duc de Bretagne, de 1402 à 1442, Société des bibliophiles bretons, Nantes, 5 vol.

Bois P. (dir.), 1977 - Histoire de Nantes, Nantes, Privat, 477 p.

Bouchart A., 1986 - Grandes Croniques de Bretaigne, CNRS éditions, Paris, nouv. éd., 3 vol.

Bougouin C., 1864 - Notice historique sur la forteresse de Pirmil, Éditeur Vve Mellinet, Nantes, non paginé.

Bourgeors L., 2013 - "Castrum et habitat des élites. France et ses abords (vers 880-vers 1000) ", in IgONA-Prat D. et al. (dir.), Cluny, les moines et la société au premier âge féodal, Rennes, Presses Universitaires de Rennes, p. 471-494.

Chédeville A. et Tonnerre N.-Y., 1987 - La Bretagne féodale $X I^{e}$-XIII siècle, Rennes, Ouest-France, $427 \mathrm{p}$.

Coativy Y., 2008 - « La bataille de Châteaubriant (3 mars 1223) : un Bouvines breton? ", in CASSARD J.-C. et al. (dir.), Le prince, l'argent et les hommes au Moyen Âge. Mélanges offerts à Jean Kerhervé, Rennes, Presses universitaires de Rennes, p. 89-101.

Contamine P., 1978 - «Les fortifications urbaines en France à la fin du Moyen Âge, aspects financiers et économiques ", Revue historique, 527, p. 23-47.

Crorx A. (dir.), 2006 - La Bretagne d'après l'itinéraire de Monsieur Dubuisson-Aubenay, Rennes, Presses Universitaires de Rennes, $1118 \mathrm{p}$.

Dreillard C., 2014 - Les enceintes médiévales de Nantes : un état documentaire de la question, Mémoire de master 1, Université de Rennes 2, 2 vol.

DREILlARD C., 2015 - Les fortifications médiévales et modernes de la ville de Nantes : étude historique et archéologique, Mémoire de master 2, Université de Nantes, 2 vol. 
Durville G., 1900 - Études sur le vieux Nantes, d'après les documents originaux, Vannes, Éditeur Vannes Imprimeur Lafolye, 2 vol.

Durville G., 1910 - "Construction du mur de ville en 1658 ", Bulletin de la société archéologique et historique de Nantes et de Loire-Inférieure, 51, p. 1-25.

Durville G., 1913 - "Les fouilles de l'évêché de Nantes, 19101913 ", Bulletin de la société archéologique et historique de Nantes et de Loire Inférieure, supplément, 366 p.

Everard J. et Jones M., 1999 - The charters of Duchess Constance of Brittany and her family, 1171-1221, The Boydell Press, Woodbridge, $217 \mathrm{p}$.

Faucherre N., 1996 - Places fortes, bastion du pouvoir, Paris, Éditions Rempart, 115 p.

FIXот M., 1980 - «Une image idéale, une réalité difficile : les villes du viI ${ }^{\mathrm{e}}$ au $\mathrm{IX}^{\mathrm{e}}$ siècle ", in Duby G. (dir.), Histoire de la France urbaine. Tome 1. La ville antique des origines au IX siècle. Seuil éditions, Paris, 1980, p. 497-563.

GuÉRIN F., 1995 - Nantes, îlot de la Boucherie. DFS de sauvetage urgent, SRA Pays de la Loire, 2 vol.

GuÉrIn F., 1998 - Nantes, rue du pont Sauvetout, rapport de fouille, SRA Pays de la Loire, 52 p.

Guigon P., 1997 - Les fortifications du haut Moyen Âge en Bretagne, Université de Rennes I, Rennes, 106 p.

Guillaume G., 2013 - « Barbetorte (Alain, 910-952) », in Croix A. (dir.), Dictionnaire de Nantes, Rennes, Presses Universitaires de Rennes, 89 p.

Guillotel H., 2014 - Actes des ducs de Bretagne (944-1148), Rennes, Presses Universitaires de Rennes, 598 p.

Науот D., 2016 - « La Tour neuve, une construction "philippienne" ? ", in Guillet B., Armide A. (dir.), Le château des ducs de Bretagne. Entre grandeur et renouveau, Rennes/Nantes, Presses universitaires de Rennes/Éditions du château des ducs de Bretagne, p. 89-93.

Jones M., 1980-1983 - Recueil des actes de Jean IV, duc de Bretagne, Paris, C. Klincksieck, 2 vol.

Jones M., 1992 - «L'utilisation de la poudre à canon et de l'artillerie dans le duché de Bretagne avant 1400 : la preuve documentaire ", Mémoires de la Société d'Histoire et d'Archéologie de Bretagne, LXIX, p. 163-172.

Jones M., 1996 - Recueil des actes de Charles de Blois et de Jeanne de Penthièvre, duc et duchesse de Penthièvre, 1364-1394, Rennes, Presses Universitaires de Rennes, 295 p.

Jouzeau M.-H., 2013 - "Château des ducs », in Croix A. (dir.), Dictionnaire de Nantes, Rennes, Presses Universitaires de Rennes, p. 214-219.

Kerhervé J., 1987 - L'État breton aux $14^{e}$ et $15^{e}$ siècles : les ducs, l'argent et les hommes. Maloine éditeurs, Paris, 2 vol.

La Borderie A., 1885 - "Variétés historiques bretonnes, II, le véritable fondateur du château de Nantes ", Revue de Bretagne et de Vendée, p. 312-317.
LA Borderie A., 1888 - Recueil d'actes inédits des ducs et princes de Bretagne ( $x i^{e}, X I I^{e}, X_{I I}{ }^{e}$ siècles), Rennes, Imprimerie Ch. Catel, $326 \mathrm{p}$.

La Borderie A., 1902 - Nouveau recueil d'actes inédits des ducs et princes de Bretagne (XIIT et XIV siècles), Rennes, Imprimerie Eugène-Prost, 210 p.

La Borderie A., 1991 - L'architecture du Moyen Âge en Bretagne, Rennes, Rue des Scribes, nouv. éd., 141 p.

La Borderie A., et Pocquet du Haut-Jussé B., 1896-1914 Histoire de Bretagne, Rennes, J. Plihon et L. Hommay, 6 vol.

Lacoste N., 2012 - Nantes, îlot d'Orléans, 22-23 Allée d'Orléans, rapport de diagnostic archéologique du bâti, DPARC, $52 \mathrm{p}$.

Lacoste N., 2014 - Nantes, porte Saint-Pierre, rapport de fouille archéologique, DPARC, $114 \mathrm{p}$.

Lallauret M., 2015 - L'église des Cordeliers de Nantes : étude de bâti du mur gouttereau nord et apports des récentes opérations archéologiques à la connaissance de l'établissement mendiant, Mémoire de master 2, Université de Nantes, 266 p.

La Nicollière-Teijeiro S., 1883 - Privilèges de la ville de Nantes, Nantes, Société des Bibliophiles Bretons, 207 p.

Laurens-Berge M., 2014a - Nantes, réseaux Flesselles-Tremperie, rapport de sondages archéologiques, DPARC, $48 \mathrm{p}$.

Laurens-Berge M., 2014b - Nantes, réseaux Maillard-Bouffay, rapport de diagnostic archéologique, DPARC, $52 \mathrm{p}$.

Laurens-Berge M., 2015 - Nantes, 2 rue Portail/5 rue Ogée, "Collégiale Notre-Dame, chapelles latérales nord", rapport de sondages archéologiques/étude de bâti, DPARC, 83 p.

Le Boulaire C., 2016 - Nantes, rue Ogée, rapport de fouille archéologique, DPARC, 2 vol.

LeguAY J.-P., 1981 - Un réseau urbain au Moyen Âge : les villes du duché de Bretagne aux XIV et XV siècles, Paris, Maloine éditeurs, 406 p.

Leguay J.-P., 2007 - « Les abords du château des ducs : SainteRadegonde, Saint-Laurent et Richebourg au $\mathrm{Xv}^{\mathrm{e}}$ siècle ", Bulletin de la société archéologique et historique de Nantes et de Loire-Atlantique, 142, p. 123-149.

Leguay J.-P. et Martin H., 1997 - Fastes et malheurs de la Bretagne ducale 1213-1532, Rennes, Éditions Ouest-France, nouv. éd., $435 \mathrm{p}$.

LeliÈvre P., 1988 - Nantes au XVIII siècle urbanisme et architecture, Paris, Picard éditeurs, éd. rev. et aug., 275 p.

Lemeillat M., 2013 - Actes de Pierre de Dreux, Duc de Bretagne (1213-1237), Rennes, Presses Universitaire de Rennes, 291 p.

Lemeillat M., 2014 - Actes de Jean I Ir, Duc de Bretagne (12371286), Rennes, Presses Universitaires de Rennes, 388 p.

Le Mené M., 1961 - "La construction à Nantes au Xve siècle ", Annales de Bretagne, 68, (3), p. 361-402.

Lobineau Dom, 1707 - Histoire de Bretagne, composée sur les titres et les auteurs originaux, Paris, Michel Guignard éditeur, 2 vol.

Lobineau Dom et al., 1741-1756 - Histoire ecclésiastique et civile de Bretagne, composée sur les auteurs et titres originaux, Paris, Charles Osmont-Delaguette, 2 vol. 
Martineau J., 2001 - Nantes, porte Sauvetout, tour d'Erdre, DFS d'étude de bâti, étude documentaire, AFAN, 2 vol.

Martineau J., 2011 - «Les tours à canon du duché de Bretagne au XV siècle ", in Prouteau N. et al. (dir.), Artillerie et fortifications, 1200-1600, Rennes, Presses universitaires de Rennes, p. 191-214.

Martineau J. et Schmitt L., 2008 - Rennes, place Saint-Germain, étude documentaire, Ligne $B$ de métro automatique, INRAP Grand Ouest, 137 p.

Mercier F., et al., 1993 - Nantes, château des ducs, Tour des Jacobins, rapport de sauvetage urgent, SRA Pays de la Loire, 3 volumes.

Mercier F. et al., 2014 - Neptune, Carré-Feydeau, rapport de fouille archéologique, DPARC, 2 vol.

Merlet R., 1896 - La Chronique de Nantes (570 environ-1049), Paris, Picard, 165 p.

MoAl L., 2009 - Nantes en 1487 : une ville en résistance, Mémoires d'histoire et d'archéologie de Bretagne, LXXXVIII, p. 75-98.

Monteil M., 2008 - "Les édifices des premiers temps chrétiens (IV ${ }^{\mathrm{e}}-\mathrm{VII}^{\mathrm{e}}$ siècle de notre ère) à Nantes ", in RousteAuСнамвоn H. (dir.), Nantes religieuse, de l'Antiquité à nos jours: Actes du colloque de l'université de Nantes, 20-21 octobre 2006, Nantes, Société archéologique et historique de Nantes et LoireAtlantique, p. 15-60.

Monteil M., 2011 - "La naissance de l'archéologie à Nantes (1500-1860) ", Annales de Bretagne et des Pays de l'Ouest, 118, (3), p. 35-53.

Morice Dom, 1742-1746 - Mémoires pour servir de preuves à l'histoire ecclésiastique et civile de Bretagne, Paris, Charles Osmont, 3 vol.

Pacaud M., 2010 - Les fortifications médiévales et modernes du cours Saint-Pierre à Nantes : étude archéologique et historique, Mémoire de master 1, Université de Rennes 2, 84 p.

PaCAud M., 2014 - «La porte Saint-Pierre : une porte de ville, un logis épiscopal ", in Faucherre N. et Guilloü̈t J.-M. (dir.), Nantes flamboyante: Actes du colloque organisé par la société archéologique et historique de Nantes et de Loire-Atlantique au château des ducs de Bretagne, Nantes 24-26 novembre 2011, Société archéologique et historique de Nantes et de LoireAtlantique, Nantes, p. 205-212.

Pascal J. et al., 2006 - Nantes, château des ducs de Bretagne, Ensemble Ouest, Rapport de sondage et analyse du bâti, INRAP Grand Ouest, $221 \mathrm{p}$.

Pascal J. et al., 2007a - Nantes, château des ducs de Bretagne, Tour du Port et cour attenante, Rapport de sondages et relevés, INRAP Grand Ouest, 128 p.

PAscal J. et al., 2007b - Nantes, château des ducs de Bretagne, Cour $d u$ château, Rapport de sondages et relevés, INRAP Grand Ouest, $141 \mathrm{p}$.
Pascal J. et al., 2008 - Nantes, château des ducs de Bretagne, Douves et pont de secours, Rapport de sondages et relevés, INRAP Grand Ouest, 209 p.

Pascal J. 2014 - «Le château des ducs de Bretagne : apport des fouilles récentes à la connaissance du déroulement du chantier ", in Faucherre N. et Guillouët J.-M. (dir.), Nantes flamboyante: Actes du colloque organisé par la société archéologique et historique de Nantes et de Loire-Atlantique au château des ducs de Bretagne, Nantes 24-26 novembre 2011, Société archéologique et historique de Nantes et de Loire-Atlantique, Nantes, p. 213-222.

Pascal J., 2016 - "Origines du site et premiers châteaux ", in Guillet B., Armide A. (dir.), Le château des ducs de Bretagne. Entre grandeur et renouveau, Rennes/Nantes, Presses universitaires de Rennes/Éditions du château des ducs de Bretagne, p. 51-85.

Pétré-Grenouilleau, O., 2003 - Nantes, Plomelin, Palantines, $299 \mathrm{p}$.

Pirault L. et Rouaud-Rouazé I., 1996 - « Les précurseurs de l'archéologie nantaise ", 303, arts, recherches, créations, 50, p. 4-19.

Pirault L. et Rouaud-Rouazé I., 1997 - « La muraille galloromaine de Nantes ", 303, arts, recherches, créations, 54, p. $13-25$.

Pocquet du Haut-Jussé B., 1929 - « Pierre Mauclerc et le conflit politico-religieux en Bretagne au XIII ${ }^{\mathrm{e}}$ siècle ", Revue d'histoire de l'Eglise de France, 15, (67), p. 137-176.

Robrie J., 1970 - « Nantes en 1646 d'après le journal de Guillaume Schellinks, ses dessins et ceux de Lambert Doomer ", Bulletin de la société archéologique et historique de Nantes et de LoireAtlantique, 109, p. 48-58.

Rouaud-Rouazé I., 1997 - Le Marchix, SRA Pays de la Loire, $83 \mathrm{p}$.

SAupin G., 1998 - Nantes au temps de l'Édit, La Crèche, Geste éditions, $287 \mathrm{p}$.

Stany-Gauthier J., 1937 - Château de Nantes, fouilles de 1936. Bulletin de la société archéologique et historique de Nantes et de Loire-Inférieure, 70, p. 46-51.

Tonnerre N.-Y., 1994 - Naissance de la Bretagne. Géographie et structures sociales de Bretagne méridionale (Nantais et Vannetais) de la fin du viiie à la fin du xii siècle, Angers, Presses de l'Université d'Angers, $625 \mathrm{p}$.

Travers N., 1836 - Histoire civile politique et religieuse de la ville et du comté de Nantes, Nantes, Imprimeur librairie Forest, 3 vol.

VANDIER J.-T.-A., 1847 - Rapport sur le Bouffai, Société historique et archéologique de Nantes et de Loire-Inférieure, manuscrit conservé au Archives municipales de Nantes (MS 1M4), 44 p.

WARnER M., 1994-1995 - "Les villes bretonnes et la guerre des sièges, 1487-1491 ", Bulletin de la société archéologique et historique de Nantes et de Loire-Atlantique, 130, p. 55-74. 
Zusammenfassung: Mittelalterliche und moderne Befestigungsanlagen der Stadt Nantes: ein Zustand des historischen, archäologischen und topographischen Wissens - Diese Studie, die sich in erster Linie auf die schriftlichen Primärquellen, auf die Ergebnisse archäologischer Ausgrabungen sowie auf kartographische Darstellungen stützt, gibt eine Übersicht zum aktuellen Stand der Erforschung der mittelalterlichen und frühneuzeitlichen Befestigungsanlagen von Nantes (Loire-Atlantique, Frankreich). Die Zusammenfassung zielt darauf ab, die zeitliche Abfolge der Befestigungswerke der Stadt, ihre topographische Situation sowie ihre Typologie von den ersten Veränderungen und Umbauten der antiken Stadtbefestigung bis zu ihrer Niederlegung während des 18. Jahrhunderts nachzuzeichnen. Dabei werden mehrere große Bauphasen der Stadtbefestigung erörtert, u.a. die Konstruktion befestigter Redouten intra- und extra-muros im Zeitraum vom 10. bis 12. Jahrhundert, die Errichtung der der großen herzoglichen Stadtmauer zu Anfang des 13. Jahrhunderts, die Arbeiten zur Verteidigung der Stadt während des bretonischen Erbfolgekrieges sowie während des Hundertjährigen Krieges, die Anpassung der Befestigungsanlagen an die Artillerie mit Schwarzpulver im 15. Jahrhundert sowie die Veränderungen während der Religionskriege. Ferner werden einige thematische Aspekte behandelt wie die Frage der Motten im Umfeld der Stadt oder die technischen Aspekte der Arbeiten zur Rekonstruktion der Stadtbefestigung im 15. Jahrhundert. Besondere Aufmerksamkeit wird auch der Präsentation der jüngsten archäologischen Ergebnisse gewidmet, ebenso wie der Darstellung von Forschungslücken, die teilweise ursächlich für eine lokale Geschichtsschreibung sind, die sich nicht immer ausschließlich auf Fakten stützte.

Resumen: Las fortificaciones medievales y modernas de la ciudad de Nantes: un balance de los datos históricos, arqueológicos y topográficos - Basándose principalmente en las fuentes textuales primarias, los datos arqueológicos y las planimetrías, el objetivo de este estudio es proponer un estado de la cuestión sobre las fortificaciones medievales y modernas de la ciudad de Nantes. Esta sintesis pretende reconstruir la evolución cronológica, topográfica y tipológica de las fortificaciones de la ciudad, desde las primeras remodelaciones del recinto galorromano hasta las obras de desmantelamiento del s. XVIII. Se analizan varias grandes fases de construcción del dispositivo defensivo urbano, como la creación de reductos fortificados intramuros y extramuros durante los siglos X-XIII, la edificación del gran recinto urbano ducal a inicios del s. XIII, las obras de fortificación de la ciudad durante la guerra de sucesión de Bretaña y la guerra de los Cien Años, la adaptación de las fortificaciones a la artillería a pólvora en el s. XV, o las construcciones relacionadas con las guerras de religión. También se desarrollan algunas cuestiones temáticas, como la de las motas periurbanas o las caracteristicas técnicas de las obras de reconstrucción del recinto urbano del s. XV. Se analizan con especial atención los datos arqueológicos, así como los vacios de documentos, que en ocasiones han originado una "tradición" historiográfica aproximativa.

Schlüsselwörter: Nantes, Stadtbefestigungen, Stadtmauer, Burganlage, castrum, Befestigungsarbeiten, Mittelalter, Frühe Neuzeit, Stadttopographie, Stadtgeschichte.

Palabras clave: Nantes, fortificaciones urbanas, recinto urbano, castillo, castrum, obras de fortificación, Edad Media, época moderna, topografía urbana, historia urbana. 